\title{
LA BRECHA AFRICANA: DESIGUALDAD LABORAL DE LA INMIGRACIÓN MARROQUÍ Y SUBSAHARIANA EN ESPAÑA, 2000-2018*
}

\section{THE AFRICAN GAP: OCCUPATIONAL INEQUALITY OF MOROCCAN AND SUB-SAHARAN IMMIGRANTS IN SPAIN, 2000-2018}

Silvia Gastón-Guiu ${ }^{\star \star}$, Rocío Treviño** y AndReu Domingo**

Resumen: La mejora del mercado laboral a partir de 2014 ha sido más lenta para la inmigración africana, ampliando la brecha entre éstos y otros inmigrantes, así como con la población nativa española, especialmente entre las mujeres. Se parte de tres preguntas: si la desventaja laboral se debe a las diferencias en nivel de instrucción; 2) si obedece a la concentración de éstos en nichos laborales de baja cualificación; y, 3) específica para las mujeres, si la incorporación al mercado de trabajo de las adultas africanas responde a un cambio de patrón generacional modificando su relación de género tradicional con el mercado laboral. Ni el nivel de instrucción ni la segregación ocupacional son suficientes para explicar la desventaja de la población africana en el mercado laboral, particularmente frente al paro y a la precariedad laboral, y especialmente entre las mujeres. Estas conclusiones nos remiten a otras razones extrademográficas que tienen que ver con el efecto neto del origen apuntando procesos de discriminación.

* Este trabajo se enmarca en el proyecto I+D dirigido por Andreu Domingo "Demografía, migraciones y nuevas fronteras estadísticas: Big Data, Registros continuos de población y Registros administrativos" (CSO2017-85670-R).

** Centre d'Estudis Demogràfics/CERCA. Universitat Autònoma de Barcelona.

MIGRACIONES 52 (2021). ISSN: 2341-0833, DOI: 10.14422/mig.i52.y2021.007 177-220 
Palabras clave: migración internacional; marroquies; subsaharianos; desigualdad; mercado de trabajo.

Abstract: The improvement in the labour market since 2014 has been slower for African immigrants. It widened the gap between them and other immigrants, as well as with the native Spanish population, especially among women. It raises three questions: Is this difference caused by differences in the level of education? 2) Is it a result of the concentration of African workers in low-skilled occupational niches? and, 3) specifically for women, is the incorporation of African adults into the labour market responds to a change in the generational pattern by modifying their traditional gender relationship with the labour market? We found that neither educational level nor occupational segregation are sufficient to explain the disadvantage of the African population in the labour market, especially in the face of unemployment and job insecurity and with greater severity among women. Our conclusions refer to some other extra demographic reasons that have to do with the net effect of the origin pointing out discrimination processes.

Key words: international migration; moroccans; sub-saharan africans; inequality; labor market.

\section{INTRODUCCIÓN: RECUPERACIÓN DEL EMPLEO Y CRECIMIENTO DE LA DESIGUALDAD}

Tras la extraordinaria caída de la inmigración durante 6 años, llegándose incluso a alcanzar saldos migratorios negativos, desde el año 2014 asistimos a la recuperación y espectacular crecimiento de los ingresos de extranjeros. En 2018 se volvieron a obtener cifras comparables a las alcanzadas en algunos de los años del boom migratorio (2005-2006) con 760.804 entradas y 840.844 las registradas en 2006. La brecha laboral ya existente entre los africanos y el resto de inmigrados, así como con los oriundos españoles, se ha acentuado respecto a la situación anterior a la crisis. Dicha brecha alude a las desigualdades en el mercado laboral en el acceso, relación contractual, posición y sector de ocupación. Las elevadas tasas de desempleo, temporalidad y parcialidad entre la población africana, junto a una marcada segregación ocupacional, evidencian la existencia de unos nichos extremadamente delimitados y perdurables en el tiempo. 
Según los microdatos de la Encuesta de Población Activa (Instituto Nacional de Estadística-INE), la tasa de paro promedio calculada para la etapa de expansión económica (2000 a 2007) fue del 18,7\% entre los africanos, del $12 \%$ entre los latinoamericanos, mientras que en los nativos españoles se situaba en el 10,1\%. Durante la crisis (2008 a 2013), se elevaron para todos registrándose una tasa del $45,1 \%$ para los nacidos en África, del 27\% para los latinoamericanos y del 18,4\% para los españoles. En la etapa de recuperación (2014 a 2018) se mantuvieron las distancias con un $42,7 \%, 25,1 \%$ y un $18,3 \%$, respectivamente. Así, aunque el nivel de paro haya descendido también para la población africana, en 2018 la brecha con los españoles se sigue sosteniendo en 19,3 puntos porcentuales, cuando en 2007, ésta era solo de 9 puntos. Su persistencia en el tiempo, y a expensas del ciclo económico, sugiere un proceso de racialización en la estructuración de los nichos laborales del mercado de trabajo español, que se traduce en una estigmatización expresada en las desigualdades de acceso al trabajo y en un peor posicionamiento en el mercado laboral (Fox et al., 2012).

Entre las mujeres, a dicha racialización y a las desventajas inherentes de la inmigración, en el mercado laboral se deben sumar las desigualdades de género. Y, aunque una de las particularidades de los flujos africanos haya sido la primacía masculina, desde finales del siglo XX se observa una progresiva feminización. Pues en 2004, según los datos de la Estadística de Variaciones Residenciales del INE, se contabilizan 31.688 entradas de africanas (28,34\% del total), mientras que en 2018 , la cifra ascendió hasta las 41.765 , lo que implica una feminización de los flujos del $34,14 \%$. Si bien este incremento viene explicado en gran parte por los procesos de reagrupación familiar. Aunque, cada vez más, cobran mayor relevancia los movimientos migratorios realizados de manera autónoma (Ribas Mateos, 2005). Pero sus protagonistas no solo manifiestan un viraje en cuanto a su volumen, sino también un cambio de actitud significativo respecto a la inserción en el mercado laboral, puesto que empiezan a declararse demandantes de empleo - activas- a partir de la irrupción de la crisis económica, como veremos más adelante. Este efecto podría corresponder a la figura de "trabajador adicional" de Humphrey (1940), definida como aquella que durante los ciclos económicos negativos se declara activa, en aras de suplir la falta de ingresos del sustentador principal del hogar en paro, y que retorna a su situación de inactividad en el momento en que 
la coyuntura se recupera. Tanto los trabajos de Prieto-Rodríguez y Rodríguez-Gutiérrez (2000) como de Congregado et al., (2011) señalan este efecto en el mercado laboral español, incidiendo en cómo la participación femenina está condicionada por la posición del cónyuge en el mercado laboral. Sin embargo, la continuación en la declaración como activas entre las mujeres africanas, podría corresponder a un cambio generacional en su patrón tradicional de actividad resultante de una mayor autonomía, libertad, empoderamiento y participación en la esfera pública (Montero y Regil, 2015).

La desigualdad en la inserción laboral de la población de origen africano en España tendrá repercusiones nefastas, tanto en las condiciones de vida de ésta y sus descendientes como en la cohesión social de la sociedad española. Efecto negativo magnificado por su número, que con más de un millón de personas en 2018, representan el $18 \%$ de todos los migrantes empadronados. Es por ello urgente medir la evolución de la situación de esta población en el mercado de trabajo y ver cómo le ha afectado la crisis y la recuperación económica reciente, sobre todo incidiendo en las causas de la brecha existente en relación con otros grupos de migrantes y con la población nativa. Por razones de representatividad de la muestra de la EPA, se ha desagregado a la población africana entre la de origen marroquí (825.674 personas empadronadas en 2018) y la del África subsahariana (256.467), mientras que, a efectos comparativos, se ha seleccionado a la población ecuatoriana (404.414) y a la rumana (593.532), contrastándolas con los nacidos en España.

Tres son las preguntas de investigación que nos planteamos verificar: la primera, si esa posición de desventaja se debe al nivel de instrucción; la segunda, si deberíamos achacarla al lugar de trabajo que ocupan; y, la tercera, específica para las mujeres, si realmente nos encontramos ante un cambio de patrón generacional en su relación con la actividad. Para responder a estos tres interrogantes, tras presentar un pequeño estado de la cuestión sobre la segmentación laboral y la población africana en España y exponer la fuente y métodos utilizados, hemos organizado el artículo en dos secciones. En la primera, realizamos una aproximación descriptiva de la situación laboral de la población africana, con especial interés en el tipo de ocupación, evolución del paro en cada uno de los períodos y la actividad femenina. Y, en la segunda, presentamos un conjunto de modelos explicativos que estandarizan el efecto de los perfiles 
sociodemográficos de los distintos grupos poblacionales (edad, sexo, nivel de instrucción, relación de pareja y tiempo de residencia) aislando el efecto neto del origen en la propensión a estar: 1) ocupado en ocupaciones elementales; 2) en paro; 3) en un trabajo precario (estandarizado por el sector ocupacional); y 4) activa según la situación laboral del cónyuge para las mujeres.

\section{POBLACIÓN AFRICANA EN ESPAÑA Y MERCADO DE TRABAJO}

Si el estudio de la inserción de los inmigrantes en el mercado laboral revela información sobre el grado de efectividad de su integración en la sociedad española (Herranz Gómez, 2000), los trabajos recientes sobre el impacto de la crisis no señalan datos muy halagüeños. La crisis económica provocó daños irreparables en el empleo durante 7 años, desembocando en elevadísimas tasas de desempleo, un abaratamiento de los costes laborales y de despido, una disminución de los salarios y de la calidad del empleo, un aumento de la temporalidad contractual y, en consecuencia, una caída del consumo (Laparra y Pérez Eransus, 2012). Los inmigrantes laborales de origen africano fueron los primeros damnificados (Recio y Banyuls, 2011; Aja et al., 2013) y ello a pesar de que los marroquíes, principal origen africano residente, contaban con la mayor antigüedad en España (Berriane, 1996, 2004; Colectivo Ioé, 2012). Así pues, la veteranía no sólo no parece haber beneficiado a la población de origen marroquí, sino que su situación marginalizada, podría estar reproduciéndose entre sus descendientes (Aparicio Gómez y Tornos Cubillos, 2006).

El mayor impacto de la crisis económica y la posición subalterna en el ámbito laboral de la población inmigrante en general y las disimilitudes halladas en relación con la población nativa, han sido analizadas desde dos perspectivas. Por un lado, desde las teorías de la asimilación ligadas al capital humano $(\mathrm{CH})$ y, por el otro, desde la asimilación segmentada, que se nutre de las corrientes teóricas recogidas por la teoría de la segmentación del mercado de trabajo (TSMT) (Simón et al., 2014).

El CH (Becker, 1964) parte de la consideración de que cada individuo cuenta con una serie de atributos —innatos o adquiridos- 
que juegan un papel determinante en la inserción en el mercado de trabajo en relación a su productividad y el salario percibido. El proceso de obtención -inversión- de cualidades adquiridas conlleva, implícitamente, la asunción de costes - directos o indirectos-. Así pues, cada trabajador debe decidir su disposición a la inversión, tras valorar los costes-beneficios, que determinarán, no sólo la cantidad de trabajo que puede asumir, sino también la calidad que podrá ofrecer en su realización.

En esta línea, uno de los trabajos más influyentes sobre la inserción laboral de los inmigrantes fue el de Chiswick, publicado en 1978, donde estudió las diferencias salariales entre extranjeros y nativos. Concluyó que, a pesar de que los inmigrantes parten de salarios inferiores, debido a la inespecificidad de su $\mathrm{CH}$, a medida que la experiencia y el tiempo de residencia aumentan en el país de destino, se redimen (Sjaastad, 1962). Pues se suele establecer una relación directa entre la mejora de posición social y económica de los inmigrantes cuanto mayor sea el tiempo transcurrido en el país de acogida, debido a un mayor dominio del idioma, de la cultura, del funcionamiento del mercado laboral e, incluso a causa del desarrollo de un sentimiento de pertenencia (Dorantes y De la Rica, 2007), lo que puede ser resumido mediante el conocido término "U-shaped" (Chiswick et al., 2005). Esta afirmación se enlaza con la transferibilidad del $\mathrm{CH}$ de un país a otro. Y es que, el $\mathrm{CH}$ acumulado previamente al proyecto migratorio es imperfecto, debido a su escaso y difícil rendimiento en el país de asentamiento (Chiswick y Miller, 2009), teniendo que adquirir uno específico o complementarlo en el país de destino, ralentizándose de este modo el proceso de asimilación con la población nativa y la adquisición de mejores puestos de trabajo (Chiswick, 1978, 1979; Weiss et al.,2003; Fernández y Ortega, 2008). Por su parte, Hagan (2004) expone que existe una relación de dependencia directamente proporcional, donde a menor distancia cultural y económica entre los países implicados en el movimiento migratorio, mayor y más fácil será el traspaso de $\mathrm{CH}$. Si bien, tal y como proponen FernándezMacías y colaboradores (2015), no solo basta con relacionar las desventajas laborales con una baja transferibilidad, sino que debería ser complementada con la comparación entre el último trabajo en origen, el primero en destino y el actual, así como incluir la inactividad y el desempleo en los análisis. En la investigación de Janta y colaboradores (2019) se examinaron el acopio y rendimiento 
de $\mathrm{CH}$ adquirido en aquellos casos en los que hay retorno al país de origen. Aunque generalmente los retornos han sido asociados con la falta de oportunidades y habilidades, consideraron que también existía la posibilidad de sacar rendimiento del retorno al país de origen, concluyendo que la movilidad internacional aumenta las habilidades, la confianza y mejora la futura empleabilidad. Por su parte, Williams (2006) y Miyar-Busto y Muñoz-Comet (2018) destacan la importancia del lugar, tanto del que se parte y se retorna como al que se inmigra. Puesto que determina la calidad de la adquisición, tanto de $\mathrm{CH}$ formal como social (Williams y Baláž, 2005). Y que, a mayor similitud en términos de desarrollo, más probable será el éxito ocupacional posterior.

Así pues, tradicionalmente, se ha considerado que el nivel educativo juega un papel determinante a la hora de explicar la posición marginalizada de los inmigrantes respecto a los nativos y en el estudio de los procesos de asimilación en el destino. Por un lado, por la inferioridad educativa formal de los inmigrantes frente a los autóctonos, sobre todo, en destinos de economías desarrolladas con una fuerte demanda de trabajos no cualificados. Por otro lado, porque el rendimiento del $\mathrm{CH}$ en destino es menor entre los inmigrantes ya que se transfiere imperfectamente en el país anfitrión (Fernández y Ortega, 2008). Y, por último, los trabajos del país de destino situados en la base de la jerarquía ocupacional resultan más atractivos para los individuos poco cualificados que los trabajos en origen, no ocurriendo lo mismo con sus homólogos nativos (Hall y Farkas, 2008).

Sin embargo, investigaciones como la realizada por Mooi-Reci y Muñoz-Comet en 2016 afirman que el nivel de estudios no sería el único factor en la inclinación hacia la propensión a la pérdida de empleo y a la no inserción, ya que los efectos coyunturales y las características estructurales del mercado laboral también juegan un papel determinante. Dicho lo cual, el $\mathrm{CH}$ y el nivel de estudios, a pesar de la gran influencia en el posicionamiento laboral, no lograría explicar las desventajas en su totalidad.

Así desde las teorías de la segmentación del mercado de trabajo, la posición desventajada de los africanos se explica mediante factores estructurales del mercado de trabajo, como son la configuración de nichos ocupacionales con características muy diferenciadas en cuanto a calidad del empleo y posibilidad de promoción, tanto laboral como social. Ante la imposibilidad del $\mathrm{CH}$ para explicar 
dichas disparidades, sobre todo a lo largo del tiempo, o la persistencia de la pobreza y las desigualdades salariales, la TSMT comenzó a cobrar relevancia explicativa. Piore, en 1969, y para superar las limitaciones de la anterior perspectiva, desarrolló su teoría en la que determina que el mercado laboral tiene una estructura dual, generada por la demanda en las economías modernas, la tecnología y la organización de la producción, donde los trabajadores pueden ser fijos o variables según la demanda, la oferta y las características del puesto (Piore, 1980a, 1980b).

El uso de esta corriente de pensamiento para entender las diferencias laborales de los trabajadores ha sido muy extenso, ya sea desde perspectivas más teóricas o aplicadas, más descriptivas o causales, poniendo más o menos énfasis en factores ligados a la oferta o la demanda y privilegiando más o menos los factores económicos, sociales, políticos, institucionales o sociodemográficos (FernándezHuerga, 2010) y la visión de un mercado dual ha ido evolucionando hacia la de una compleja fragmentación de nichos laborales. Sin embargo, en su concepción más básica, se entiende que el mercado de trabajo está formado por, al menos, dos segmentos: el primario y el secundario. En el primario, por su parte, quedan aglutinados los empleos de alta competencia, mientras que en el secundario se encontrarían aquellas ocupaciones de baja cualificación. Según esta perspectiva, el mercado de trabajo español muestra claros signos de dualización debido a la amplia demanda de empleo de ocupaciones de baja cualificación que componen el segmento secundario, donde las posibilidades de promoción son muy reducidas, además de sufrir los impactos, en términos de creación-destrucción de empleo, en los cambios coyunturales (Carrasco et al., 2008; Muñoz Comet, 2012). En esta línea, Pumares y colaboradores (2006) realizaron un análisis de la inserción en el mercado de trabajo y la movilidad — ascendente o descendente- laboral y geográfica a partir de las altas en la Seguridad Social, en el que se atisbó cierta movilidad ascendente de la población inmigrante a nivel intrasectorial. Esto significa que, dentro de un sector de actividad afincado en el segmento secundario, puede haber promoción, siendo más difícil la movilidad extrasectorial. Si bien, los movimientos laborales adquieren diferentes tendencias según el sexo, origen y edad, entre otros atributos. Y, es que, la TSMT se encuentra íntimamente relacionada con la estratificación económica, social, de género y étnica-etnoestratificación- (Doeringer y Piore, 1971; Piore, 1969, 1975). 
La etnoestratificación alude a la evidencia de la inserción mayoritaria por parte de la población inmigrante en las ocupaciones del segmento secundario, generándose dinámicas de desigualdad étnico-migratorias en base al origen (Noel, 1968; Grande et al., 2016), que limitan la movilidad entre sectores de actividad — movilidad horizontal - y entre categorías ocupacionales — movilidad vertical(Fernández-Macías et al 2014). Del mismo modo, Gil y Domingo (2008), Muñoz-Comet (2013) y Carrasco Carpio y García-Serrano (2015), a partir del análisis de los datos de la EPA en los periodos desde 2000 a 2005, 2005 hasta 2010 y de 2008 a 2013, respectivamente, determinaron la predisposición de la población extranjera a ocupar los empleos de baja cualificación formándose nichos específicos denominados como trabajos de inmigrantes (Massey et al., 1987). Así como el aumento de la probabilidad, en caso de pérdida de empleo, de ocupar uno nuevo de características similares. Además de los ya citados, en España son muchos los trabajos que se han realizado sobre la asimetría entre los segmentos en base al origen, destacando los de Cachón Rodríguez (2002, 2003, 2009); Carvajal y Pumares (2004); y Valero-Matas y colaboradores (2014). En ellos se evidencia que, la mayoría de los africanos y africanas aparecen adscritos al segundo segmento o en ocupaciones con condiciones de trabajo precarias, bajos salarios, escasas probabilidades de promoción a empleos que garanticen mejoras y con gran movilidad entre puestos de trabajo inestables (Posso, 2010) y, en cambio, escasamente representados en el primer segmento.

Pero también las diferencias ocupacionales por razón de género atraviesan toda la sociedad, y se imponen como uno de los ejes de segmentación del mercado laboral que, junto con la edad y la racialización de las mujeres inmigradas, agravan su subordinación laboral, sus condiciones de trabajo y salario, así como la posibilidad de acceso no sólo al mercado laboral en general sino también a determinados sectores de la actividad (Molpeceres Álvarez, 2012; Iglesias et al., 2015). Estudios como el de Fernández-Macías y colaboradores (2015) exponen el reciente cambio de rol de las mujeres inmigrantes, apreciándose ahora que las recién llegadas tienen mayor predisposición a formar parte de la población activa del país de destino que con anterioridad. No obstante, las mujeres se enfrentan a una doble desventaja, donde el género añade otra dimensión de estratificación en las inmigrantes, tanto en el mercado laboral como en la sociedad. Esta dimensión, al combinarse con 
el estatus de inmigrante proporciona mayores dificultades en la inserción, pues se amalgaman los efectos negativos que acarrean el origen y el ser mujer (Boyd, 1984). Raijman y Semyonov (1997) investigan la existencia de dicha desventaja y evidencian la interacción entre el género y la etnicidad en el aumento de las dificultades y menores probabilidades de insertarse en el mercado de trabajo del país de destino. Si bien, añaden una connotación más específica. $\mathrm{Y}$ es que, también distinguen por lugar de origen, dando cuenta de que, las mujeres provenientes de países menos desarrollados (África y Asia) sufren más las desventajas. En este caso, las autoras hablan de una triple discriminación - género, origen y desarrollo del lugar de origen-.

Para el caso español, Fernández-Macías et al., (2015) realizaron un análisis de la movilidad ocupacional y la empleabilidad de los y las inmigrantes acabados de llegar en el periodo temporal que abarca desde 1997 a 2007. En el mercado de trabajo español se aprecian grandes disimilitudes por género. Por ejemplo, los hombres africanos se encuentran sobrerrepresentados en sectores de actividad de baja cualificación con tendencia a resentirse durante los ciclos económicos negativos —construcción, hostelería y restauración-; otros sectores, en contraste, ocupados generalmente por mujeres, han tenido mayor resistencia a las fluctuaciones económicas de la última recesión, aunque con propensión a la precarización servicio doméstico y ayudantes de cocina-(Garson y Dumont, 2009; Miguélez y López-Roldán 2014). Es por ello por lo que el estudio de la inserción en el mercado laboral diferenciando por género es crucial en tanto en cuanto a la existencia de dichas diferencias y por la incuestionable paulatina feminización de los flujos migratorios en las últimas décadas (Fernández-Macías et al., 2015).

Así pues, una vez realizado el recorrido por las referencias teóricas que ayudan a explicar el problema objeto de estudio que aquí proponemos, se puede sustraer que la segmentación puede verse motivada e incrementada por un motivo en concreto o por la mezcla de varios de ellos como sería el origen, edad, género o nivel de instrucción. Sin olvidar los factores económicos y estructurales del mercado o coyunturales. Todos estos factores repercuten directamente en el modo en el que los individuos participan en el mercado laboral (Gil y Domingo, 2008) e intervienen en la "asignación" de la población en cada segmento. De este modo, en el presente trabajo se han seleccionado las variables explicativas 
sociodemográficas pertinentes, como se indican en el siguiente apartado, para dar respuesta a los objetivos y contrastar las hipótesis de partida.

\section{FUENTES Y METODOLOGÍA}

Se han utilizado los microdatos trimestrales de la Encuesta de Población Activa (EPA) de 2000 a 2018, destacando tres períodos de análisis según el ciclo económico: 1) 2000-2007: Expansión; 2) 20082013: Recesión; y, por último, 3) 2014-2018: Recuperación. También se han distinguido cinco grupos poblacionales en el análisis en función del país de nacimiento: Marruecos, África Subsahariana, Rumanía, Ecuador —orígenes de mayor peso poblacional- y España. Y, además de emplear el origen como eje transversal de análisis, se consideraron las variables de sexo y edad - jóvenes (1629) y adultos (30-64).

La EPA tiene una periodicidad trimestral y cuenta con una muestra aproximada de 60 mil hogares por trimestre. En cada trimestre se renueva una sexta parte, con lo que la sustitución total de la misma se produce al cabo de seis. Por esta razón, y para minimizar las observaciones repetidas entre trimestres - probablemente inferiores entre la población extranjera-, se agruparon, únicamente, los segundos trimestres de los periodos mencionados en los análisis multivariantes. Sin embargo, en los descriptivos — tasas de paro, actividad y distribución ocupacional- se acumularon anualmente con el propósito de suavizar las curvas que aparecen zigzagueantes debido a la escasez de la muestra de residentes de algunos orígenes al desagregarse. El número mínimo de casos por origen corresponde a las mujeres subsaharianas en el periodo de expansión (621 mujeres).

Es necesario destacar tres aspectos en la recogida de datos y clasificación que afectaron a nuestra observación. En primer lugar, el cambio en la definición de paro en 2002 haciéndola más restrictiva. En segundo, el censo de 2011 permitió mejorar los pesos de la población extranjera, que anteriormente se encontraba muy subestimada, proporcionándonos nuevos ficheros que han sido incorporados. Por último, en ese mismo año, se introdujo un cambio en la Clasificación Nacional de Ocupaciones (CNO), sustituyéndose la de 1994 (CNO-94) por una nueva (CNO-11). 
Ésta última se encuadra en un nuevo marco conceptual, el de la clasificación internacional de ocupaciones (CIUO-08), que incluye en los criterios de clasificación, además del tipo de trabajo realizado, las competencias para su desempeño.

Esta variación imposibilita la armonización individual de la variable "Ocupación" a lo largo del periodo. A nivel agregado, el INE proporciona una matriz de ponderaciones para reasignar las ocupaciones de la CNO-94 a la nueva clasificación ${ }^{1}$, que ha sido utilizada a nivel descriptivo. Ante el impedimento de poder trabajarla de forma homogénea a nivel individual en los microdatos y, por tanto, en los modelos multivariables, se ha optado por utilizar las CNOs específicas para los periodos completos —expansión y recuperación-. En el correspondiente a la crisis, que comprende años con distintas clasificaciones, cuando se incluye la variable tipo de ocupación, los datos corresponden en los modelos a los años 2011-2013.

Se ha utilizado la regresión logística binomial para calcular la probabilidad de ocurrencia de los eventos (ocupación elemental, paro, precariedad laboral, actividad laboral) tomando una variable dependiente con dos opciones de respuesta mutuamente excluyentes (presencia -1- o ausencia -0-) partiendo de la ecuación:

$$
P(Y=1 \mid X)=\frac{\exp \left(b_{0}+\sum_{i=1}^{n} b_{i} x_{i}\right)}{1+\exp \left(b_{0}+\sum_{i=1}^{n} b_{i} x_{i}\right)^{\prime}}
$$

Donde:

$P(Y=1 \mid X)$ : Es la probabilidad de que $\mathrm{Y}$ tome el valor 1 .

$\mathrm{X}=$ Conjunto de covariables $\left(x_{1} \ldots \ldots \ldots x_{n}\right)$

$b_{0}=$ Denota a la constante del modelo.

$b_{i}=$ Son los coeficientes de las covariables.

Mediante su aplicación se han obtenido las odds ratio (Exp (B)) de los modelos mutivariables de cada uno de los eventos. Los modelos se hacen separados por período y sexo. Así las variables dependientes (Y) son:

1) $1.1 \mathrm{Y}(0=$ otro trabajador y 1 = trabajador no cualificado $)$ CNO-94 para el período de expansión.

$1.2 \mathrm{Y}(0=$ ocupado en ocupaciones no elementales y $1=$ ocupado en ocupaciones elementales) - CNO-11 para el de crisis (sólo años 2011-2013).

1 Ver: https://www.ine.es/daco/daco42/daco4211/nota_epa_retro0011.pdf 
2) $\mathrm{Y}(0=$ ocupado y $1=$ parado $)$ para los tres periodos

3) $\mathrm{Y}(0=$ trabajador no precario y $1=$ trabajador precario $)$, sólo para el período de recuperación.

4) $\mathrm{Y}(0$ = no activa y $1=$ activa $)$ para los tres periodos, pero sólo para las mujeres.

A nivel descriptivo, las ocupaciones de toda la serie se han agrupado agregando algunos de los grandes grupos de la clasificación de la CNO-11: el primero, comprende los 4 primeros grupos (directores, gerentes, técnicos, profesionales, contables y trabajadores de oficina); el segundo, el quinto (trabajadores de la restauración, vendedores, servicios personales y de protección); el tercero, el sexto (trabajadores agrícolas, pesqueros ganaderos y forestales cualificados); el cuarto, el séptimo y octavo (artesanos y cualificados de la industria y construcción, así como operadores de maquinaria y montadores); el quinto, las ocupaciones elementales. Éstas comprenden empleados domésticos y otro personal de limpieza, vendedores ambulantes, ayudantes de cocina y peones de todos los sectores. Las ocupaciones militares se han excluido en la representación.

En los modelos, se ha utilizado la categoría específica de 'trabajador cualificado' de la CNO-94 para el periodo de expansión y de 'ocupación elemental' para el periodo de crisis que, para salvaguardar la homogeneidad solo refiere a los años 20112013. Ambas rúbricas expresan ocupaciones análogas, pero sin correspondencia absoluta por la mencionada ruptura conceptual. Según las reponderaciones del INE, cabría clasificar el 95\% de las ocupaciones no cualificadas según la CNO-94 del período 2000-2007 como ocupaciones elementales según la CNO-11.

Se considera que un individuo está en una situación de precariedad laboral si su ocupación cumple con al menos uno de estos criterios: 1) contrato temporal; 2) trabaja habitualmente más horas que la media, más una desviación estándar de las horas trabajadas en su sector ocupacional y quiere trabajar menos horas y; 3) si trabaja menos horas que la media en su sector ocupacional, menos una desviación estándar y quiere trabajar más horas. Para la elaboración de esta variable derivada se ha tenido en cuenta la CNO-11 de 17 categorías ocupacionales (excluyendo las ocupaciones militares).

Como variables independientes $(\mathrm{X})$ se han seleccionado un conjunto considerado como imprescindible en el estudio de la inserción laboral de la población inmigrante —edad (16-29 y 30- 
64), sexo, origen (definida por el lugar de nacimiento), ocupación, situación de pareja (unido, no unido), años de residencia en España (menos de un años, de 1 a 5 años, más de 5) y nivel de instrucción-, homogenizando las clasificaciones nacionales de educación CNED2000 y CNED-2014 y distinguiendo tres niveles. La instrucción elemental comprende hasta la educación primaria; el nivel medio, la primera y segunda etapa de secundaria, tanto la general como la de orientación profesional; finalmente, la superior, que corresponde con los estudios universitarios. Para evitar introducir interacciones, se han realizado los modelos separados por sexo y en ocasiones distinguiendo un modelo para jóvenes y otro para adultos. Además de realizar modelos específicos para inmigrantes, donde se introduce la variable del tiempo de residencia en España.

\section{SITUACIÓN LABORAL DE LA POBLACIÓN AFRICANA EN ESPAÑA}

\subsection{La distribución ocupacional}

La distribución en 2018 por ocupaciones confirma la posición subalterna de los inmigrantes, lo que evidencia la dualización del mercado de trabajo español (Figura 1). Así, advertimos, por una parte, unas ocupaciones que se situarían predominantemente en el segmento primario - los profesionales, técnicos y personal de oficina-, donde está empleado un $40 \%$ de todos los oriundos españoles que trabajan y donde casi no encontramos inmigrados, con un peso casi siempre por debajo del 10\% entre los hombres y solo rebasado por las mujeres en el periodo de expansión. Por otra parte, en las ocupaciones elementales, bandera del secundario, contrariamente, se encuentran sobrerrepresentados los inmigrados, con porcentajes que van de un $38 \%$ para los hombres marroquíes durante los tres períodos y que alcanzan en las mujeres el 47,6\% en el de crecimiento y el $57 \%$ en la recuperación; mientras que, en los españoles apenas llegan a un 7\%, casi doblándolo las españolas (13\%). La asimetría entre la población nativa e inmigrada es evidente. Pero, además, esa posición no ha mejorado con el tiempo para los africanos frente a la mejora que sí han experimentado el resto de los trabajadores de otros orígenes. 
FIgURA 1

DISTRIBUCIÓN OCUPACIONAL POR PAÍS DE NACIMIENTO

(ÁFRICA - MARROQUÍES Y SUBSAHARIANOS-,

RUMANÍA, ECUADOR Y ESPAÑA) Y SEXO.

2000-2007, 2008-2013 Y 2014-2018
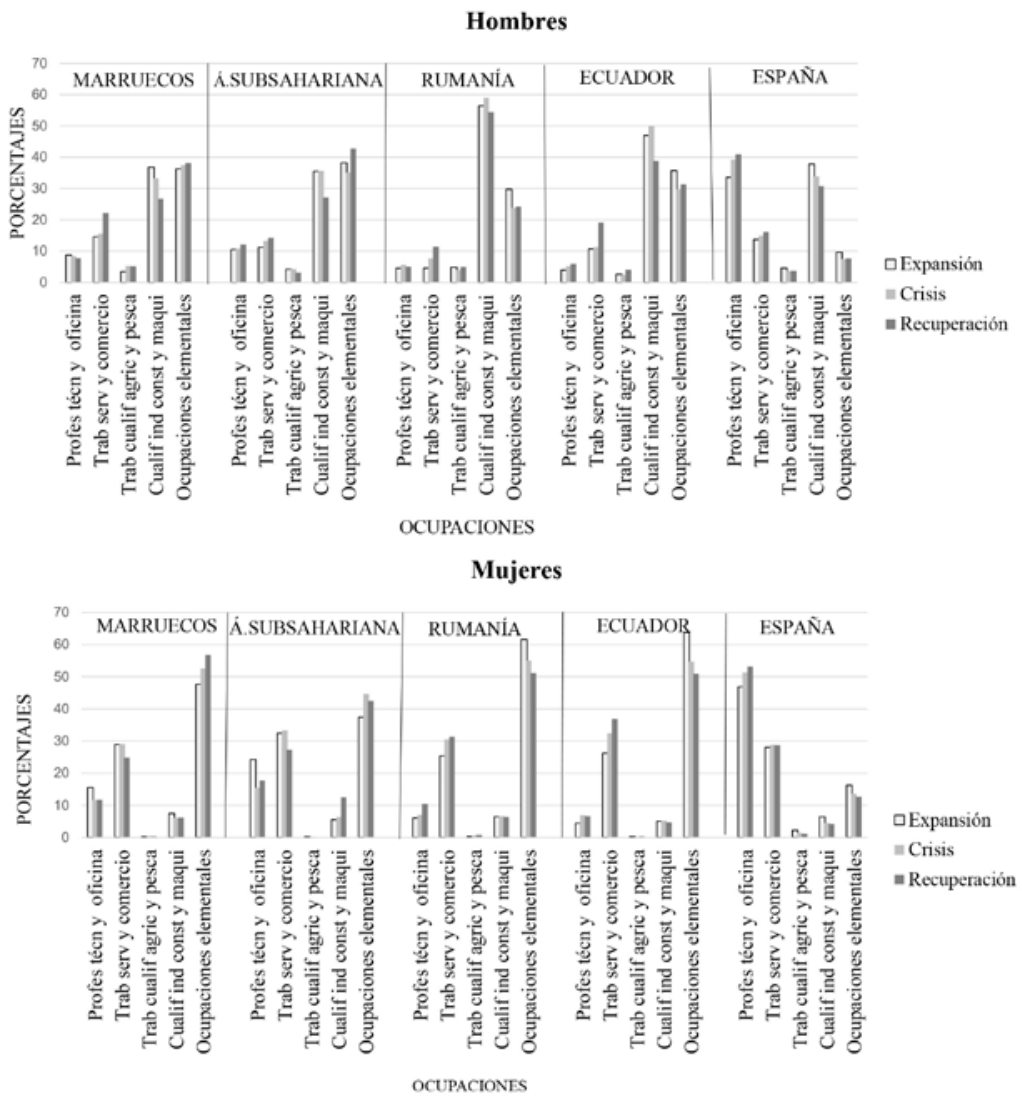

*Nota: no se representan las ocupaciones militares.

Fuente: elaboración propia, Encuesta de Población Activa, 2000-2018 (INE).

Así, casi 4 de cada 10 hombres marroquíes tienen un empleo ubicado en la categoría de ocupaciones elementales en las tres coyunturas económicas, incrementándose esta concentración sólo muy ligeramente; en cambio, en la recuperación parece producirse 
un cierto trasvase de las ocupaciones cualificadas de la construcción e industria a las ocupaciones de los servicios y comercio. En los subsaharianos, el porcentaje de trabajadores en ocupaciones elementales sobrepasa ligeramente a sus homólogos africanos e incrementa a lo largo del periodo en 4 puntos y se produce también en la recuperación una disminución del peso de los trabajos cualificados de la industria y construcción. La presencia de ecuatorianos y sobre todo rumanos en los trabajos cualificados de la industria y construcción sigue siendo muy superior a la de los africanos, a pesar de que también experimentan, en particular los ecuatorianos, un detrimento de estas ocupaciones a la par que un aumento de la ocupación en los servicios, hostelería y comercio. Debemos tener en cuenta que el escenario desigual entre los trabajadores en España, en gran medida, ha sido generado no sólo por la dualidad sino también por los procesos de reestructuración sectorial y de especialización, que han desembocado en la terciarización de la economía. Tras la recesión, comenzó el menoscabo del sector de la construcción y gran parte de sus puestos de trabajo manuales fueron destruidos, produciéndose un trasvase de empleos hacia el sector de la hostelería y restauración —cambio intra-sectorial- (Cuadrado Roura e Iglesias Fernández, 2003).

Para las mujeres africanas, el deterioro de su posición en la jerarquía ocupacional es más acusado y contrastado con el resto de las inmigrantes de otros orígenes. Disminuyen su peso las profesionales y las trabajadoras de los servicios y restauración e incrementan las ocupaciones elementales. Mientras que las mujeres rumanas y ecuatorianas presentan la evolución inversa. Y las nativas y nativos aumentan su concentración en la cúspide de la pirámide de la jerarquía ocupacional.

\subsection{Evolución del paro y precarización del empleo}

La Figura 2, al tiempo que dibuja con nitidez las diferencias halladas en las tasas de paro en los tres ciclos económicos, señala el ensanchamiento de éstas por origen en los periodos de crisis y recuperación. Las tasas de paro de todos los grupos toman valores muy elevados, despuntando las de la población africana desde la expansión. Durante la crisis, el desempleo de los hombres inmigrantes se dispara en relación con la población nativa, pero los africanos 
agrandan la desventaja con el resto. En la etapa de recuperación, continúan reportando cotas más elevadas que los demás, a pesar de haber mejorado su situación respecto a la etapa de crisis - reduciendo la tasa a la mitad desde el punto máximo alcanzado en 2013, con un $52,4 \%$ para los marroquíes y un $48,4 \%$ para los subsaharianos, hasta un $28 \%$ en ambos grupos en 2018- . La tendencia hacia la recuperación masculina se da a partir de 2013 entre los nativos y un poco más tarde los inmigrados, aunque de manera desigual. De este modo, si la brecha entre marroquíes y españoles se situaba en sólo 6,2 puntos porcentuales en el período álgido del empleo (2006) y en 5,9 en el caso de subsaharianos (2007); en 2018, pese a la consabida reducción del paro para todos, esa distancia entre españoles y marroquíes se multiplica por 2,5 y por 2,6 con los subsaharianos, llegando a los 15,5 puntos porcentuales, mientras que ecuatorianos y rumanos sólo distaban 5,7 y 3,5 puntos respectivamente, niveles superiores a los registrados en 2005 y 2006, cuando las diferencias entre los nativos españoles y estas nacionalidades eran mucho menores.

En las mujeres africanas esas disparidades, sistemáticamente superiores que las de los hombres, aún han resultado más estridentes a medida que se han ido incorporando nuevas activas. Así, en el período de expansión del empleo, las relativamente escasas activas africanas, presentaban porcentajes de desempleo del 29\% para las marroquíes y del $27,9 \%$ las subsaharianas en 2007, cuando las españolas acumulaban el 10,2\%, a las que se aproximaban tanto las ecuatorianas $(10,6 \%)$ como las rumanas $(14 \%)$.

En 2018, el paro de las marroquíes y subsaharianas, que había llegado a superar más de la mitad de las activas en los peores años de la crisis, sigue siendo del $45,2 \%$ para las primeras y del $43,7 \%$ para las segundas, cuando las nativas están al 15,8\%. Es decir, mantienen una brecha respecto a las españolas de 32,6 puntos, y de 27,5 respectivamente, muy por encima de la distancia que separa a las españolas de rumanas (6,8 puntos porcentuales) y de ecuatorianas (2,6 puntos).

En la Tabla 1 se presentan algunos indicadores de precariedad laboral, mostrando la edad y el sexo como ejes de segmentación. Los jóvenes tienen porcentajes de temporalidad y paro superiores que los adultos en ambos sexos, para todos los orígenes y periodos. Por sexo, se constata que el trabajo a tiempo parcial se sitúa constantemente por encima entre las mujeres y el porcentaje de autónomos lo hace entre los hombres. En cuanto a la tasa de paro, entre las mujeres 
FigURA 2

TASAS DE PARO POR PAÍS DE NACIMIENTO (ÁFRICA MARROQUÍES Y SUBSAHARIANOS-, RUMANÍA, ECUADOR

Y ESPAÑA) Y SEXO. 2000-2018

\section{Hombres}

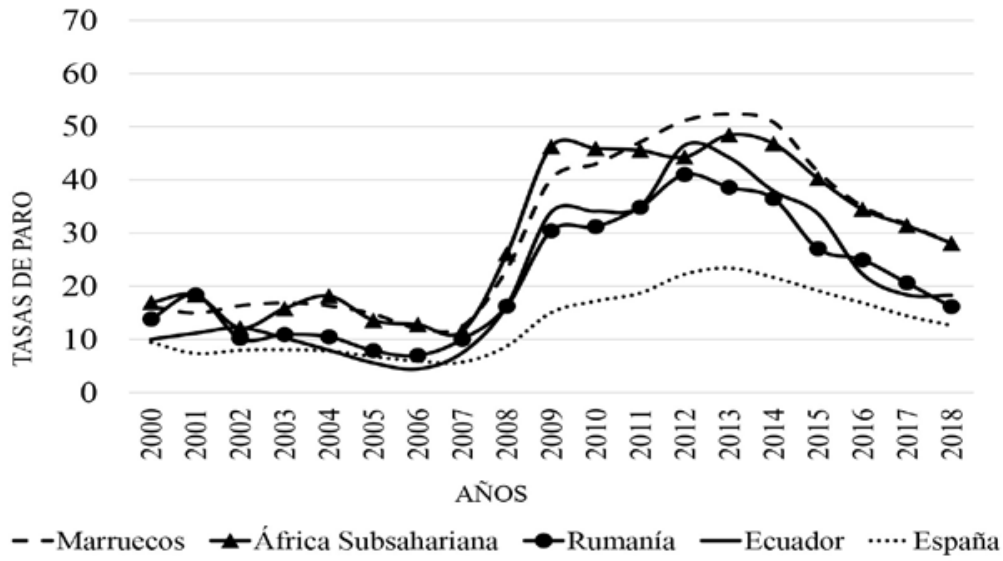

\section{Mujeres}

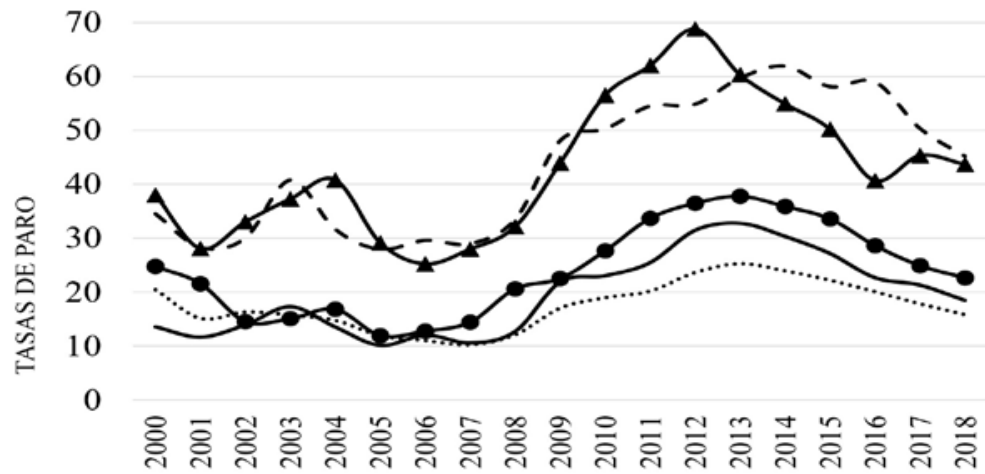

AÑos

- Marruecos $₫$ África Subsahariana $\rightarrow$ Rumania —Ecuador … España

Fuente: elaboración propia, Encuesta de Población Activa, 2000-2018 (INE). 
jóvenes se encuentran los mayores porcentajes para todos los orígenes, equilibrándose durante la crisis y la recuperación las tasas de ecuatorianas y nativas, así como con la obtenida por los hombres en los mismos periodos. Entre la población adulta se manifiesta un patrón similar, pues las tasas más altas recaen sobre ellas, excepto las rumanas, ecuatorianas y españolas durante la crisis y recuperación. El paro golpea a los africanos de ambos sexos y grupos de edad con mayor intensidad que al resto de grupos en todas las coyunturas y las diferencias con los otros grupos de inmigrantes son máximas entre los jóvenes en la crisis y entre las mujeres en la recuperación. En la recuperación también destacan los elevados porcentajes de temporalidad de los africanos frente a los otros orígenes. Otra característica no coyuntural es la temporalidad, invariablemente superior entre los inmigrantes que entre los nativos, en jóvenes y adultos, en hombres y mujeres y en todos los periodos. Durante la expansión, los jóvenes africanos presentaban las distancias más acusadas en relación con los nativos — de 24 puntos porcentuales en el caso de marroquíes y de 28 de los subsaharianos; mientras que era de 20 respecto a ecuatorianos y rumanos- Sin embargo, entre las mujeres jóvenes, las brechas de temporalidad respecto a las nativas eran menores, especialmente si reparamos en las ecuatorianas, que solo alcanzaban 8 puntos. A pesar de obtener tasas más elevadas respecto a la población nativa, se aprecia un descenso generalizado desde la expansión hasta la recuperación, lo que podría explicarse por la intensa destrucción del empleo temporal y precario durante la crisis. Durante la recuperación económica, notoriamente entre la población adulta, la distancia entre africanos y la población nativa sigue siendo muy alta, incrementándose entre las mujeres. Las diferencias en la prevalencia de temporalidad con la población nativa adulta son de 32 puntos porcentuales con la población marroquí y de 27 con la subsahariana, frente a los 19 puntos de los rumanos y los 21 de los ecuatorianos.

\subsection{El cambio de patrón de la actividad femenina}

En la evolución de las tasas de actividad en los tres períodos (Figura 3) llama la atención la expansión de la actividad entre las nativas españolas, marroquíes y subsaharianas en contraste con el patrón de ecuatorianas y rumanas que, desde el principio, presentan 
tasas similares a las de la actividad masculina, con valores superiores al $80 \%$ ya a los 20-24 años y que no decrecen hasta el grupo 55-59, $60 \%$, en el primer período 2000-2007, yendo siempre por delante las rumanas. La crisis llevó a incrementar la participación de ambos orígenes, aunque más en los últimos grupos de edad. En el periodo de recuperación, las entradas de las jóvenes se han ralentizado descendiendo la tasa 16 puntos porcentuales entre las ecuatorianas de 20-24 años, entretanto el resto de las edades mantenían sus máximos cercanos al 90\% y del 78\% en el grupo 60-64. Una vez más, con menor intensidad, es lo observado para las rumanas con una entrada más tardía entre las jóvenes y un sostenimiento de las tasas en valores superiores al $80 \%$, aunque aquí la salida es anterior, con una participación del grupo 60-64 menor al 50\%.

No sucede lo mismo con las nativas españolas, que desde el año 2000 están ampliando su declaración de actividad, en lo que debemos interpretar como un cambio generacional, ya iniciado con anterioridad a la crisis. De este modo, en el período de expansión el máximo porcentaje lo encontrábamos entre las jóvenes de 25 a 29 años con un 79,3\%, pero a partir de esa edad, la participación decaía regularmente, coincidiendo con el matrimonio, llegando a ser inferior a la mitad a los 50-54 años. Con la crisis la pauta por edades prosigue, pero intensificando la participación en todas ellas. En el último período, 2014-2018, el punto de partida es el mismo $85,5 \%$ para las de 25-29 años, pero ahora ya han sido superadas por las de los dos grupos sucesivos de 30 a 34 y de 35 a 39, con sendos porcentajes de 88,5 y $87,4 \%$.

Si observamos, en cambio, a las mujeres marroquíes, lo primero que llama la atención es la inferior participación y un crecimiento, tanto en la entrada para las edades más jóvenes como en las edades más maduras. Así, en 2000-2007, la máxima actividad se centraba en el grupo 35-39 años, con un 48,2\%, para descender progresivamente. El impacto de la crisis significó elevar el grupo modal a los 40-44 años con una tasa de más del $56,9 \%$, produciéndose unos incrementos significativos tanto en el intervalo de edad de 20 a 29 años como aún más en los grupos mayores, en lo que entonces podía tomarse como el efecto adición: eran las esposas y madres las que se declaraban activas, por encima del crecimiento de las hijas más jóvenes. En el último período de recuperación 2014-2018, el grupo con más participación sigue siendo el de los 40-44 años, con un 61,5\%, situándose el resto con valores por encima de las más jóvenes hasta 


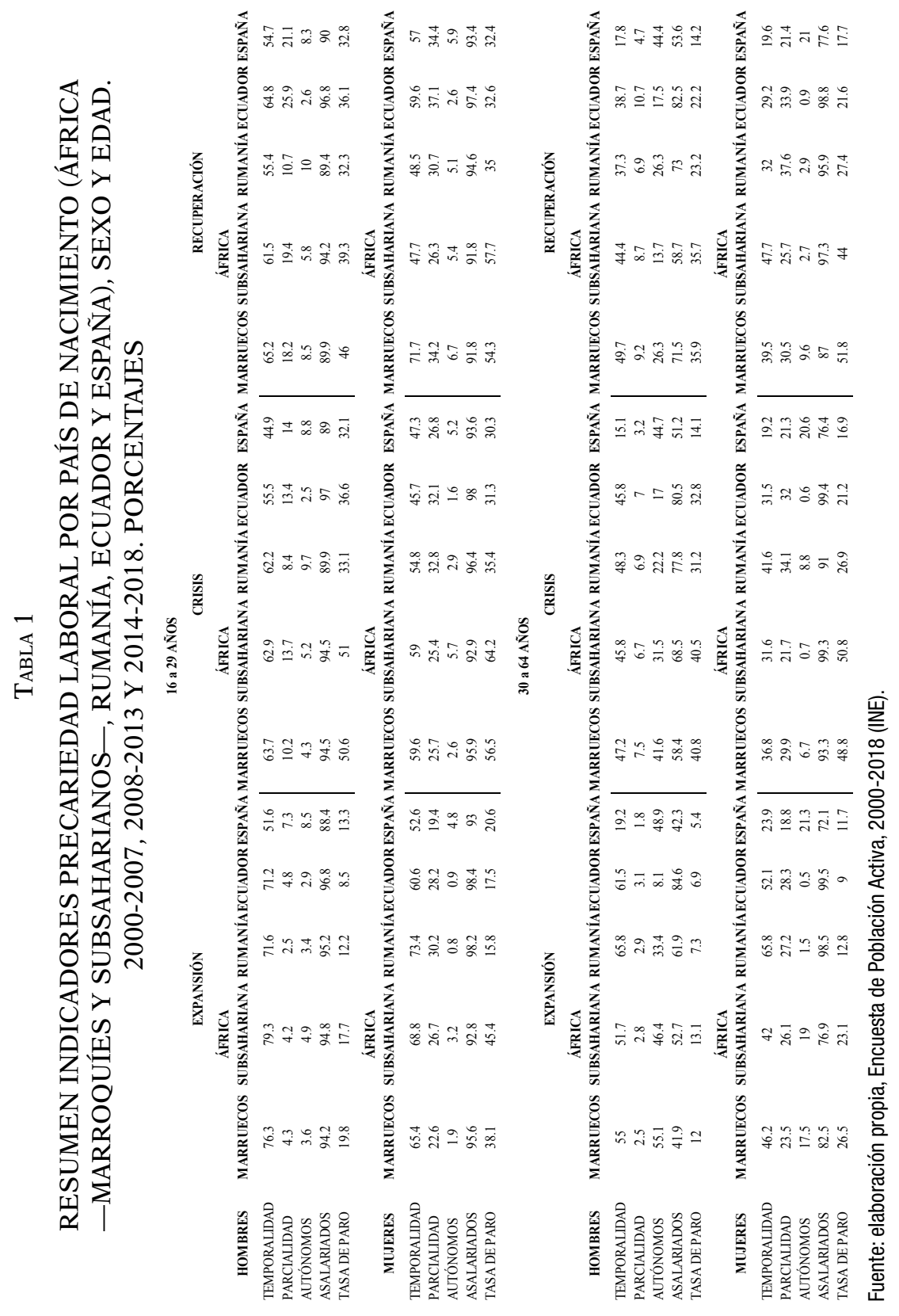


el grupo 55-59, registrando incluso un leve retroceso para las de 2529. Ese resultado cuestiona parcialmente la hipótesis del cambio generacional para las jóvenes, aunque podemos sospechar que parte de éstas puedan declararse estudiantes, no sabemos si ese retroceso se debe a la mejora experimentada por sus respectivos cónyuges o si el efecto pudiera relacionarse con el tiempo de residencia en España.

FIGURA 3

TASAS DE ACTIVIDAD POR PAÍS DE NACIMIENTO (ÁFRICA -MARROQUÍES Y SUBSAHARIANOS-, RUMANÍA, ECUADOR Y ESPAÑA) Y EDAD. MUJERES, 2000-2007, 2008-2013 Y 2014-2018
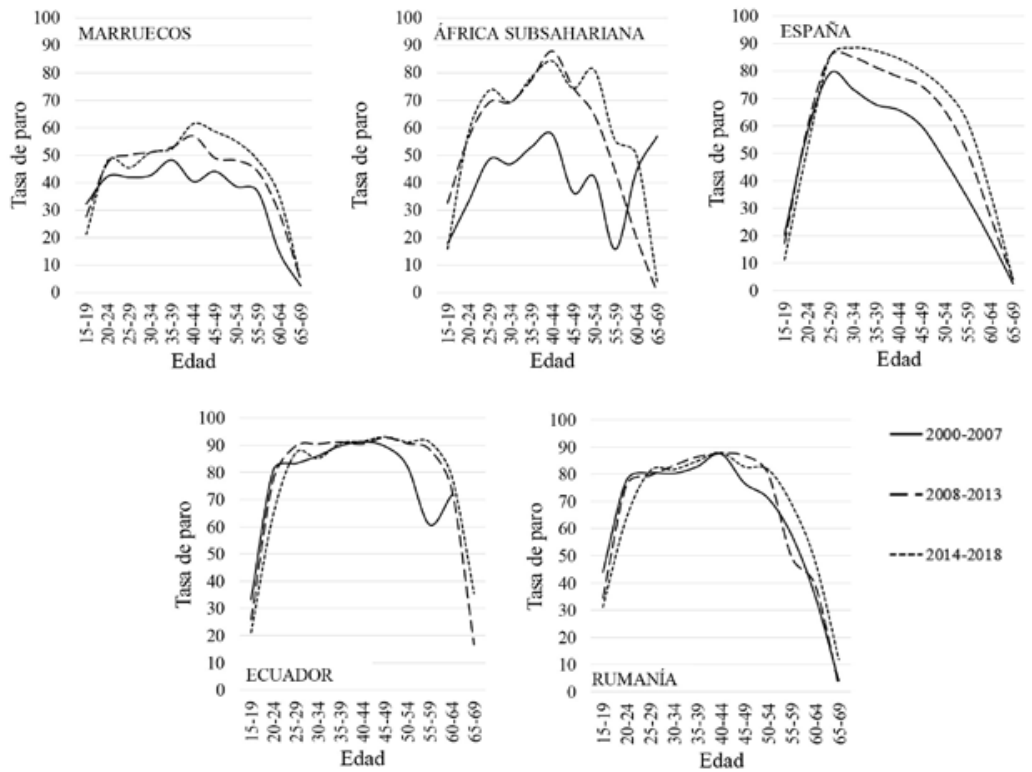

Fuente: elaboración propia, Encuesta de Población Activa, 2000-2018 (INE).

Por último, las tasas de actividad para las subsaharianas deben interpretarse con mucha más cautela debido al reducido tamaño de la muestra. Se sigue la pauta ya observada para las marroquíes: la máxima actividad se da no para las más jóvenes, sino para las mujeres entre 40 
y 44 años en los tres períodos, aunque aumentando sustancialmente en el período de crisis al pasar del $57,4 \%$ al $87,8 \%$. El crecimiento para las primeras edades, si bien menor y con un patrón parecido a las marroquíes, por su elevada intensidad las acerca a los perfiles del resto de mujeres, con porcentajes a los 25-29 años del 73,6\%

\section{MODELOS EXPLICATIVOS: LA BRECHA LABORAL POR ORIGEN}

Para responder a las preguntas planteadas al inicio se presentan, a continuación, diferentes modelos logísticos binarios. Se trata de ver, primeramente, si el menor nivel educativo de los africanos (un $47,8 \%$ de los ocupados marroquíes y un $41 \%$ de los subsaharianos poseen un nivel de instrucción elemental frente a un 7,7 de rumanos y a un 15,8 de los ecuatorianos en la etapa de recuperación) explica su concentración en ocupaciones elementales y anula el efecto de las diferencias por origen en la propensión a trabajar en este nicho ocupacional de alta precariedad. En segundo lugar, si en el primer indicador de precariedad laboral, el paro, la posición de desventaja de la población africana se sigue mostrando, una vez controlado el impacto de las diferencias de los niveles educativos, además de las variables de edad y sexo, pues ambas se han mostrado relevantes en el descriptivo. En tercer lugar, si la mayor precariedad laboral de la población africana se debe exclusivamente a que trabajan en sectores precarios o si, aun teniendo en cuenta las condiciones diferenciales de precariedad de estos sectores, siguen manifestándola en mayor grado que el resto de los grupos. Por último, y en relación con la actividad laboral de las mujeres africanas, conocer cuán sensible es su participación laboral a su situación familiar en los tres periodos, para vislumbrar si el incremento de actividad durante la crisis y recuperación se acompaña de un cambio de patrón generacional compatible con una transformación de los roles de género.

\subsection{Brecha en ocupación elemental}

En la Tabla 2 aparecen 8 modelos distintos que analizan la asociación entre diferentes variables independientes y la propensión 


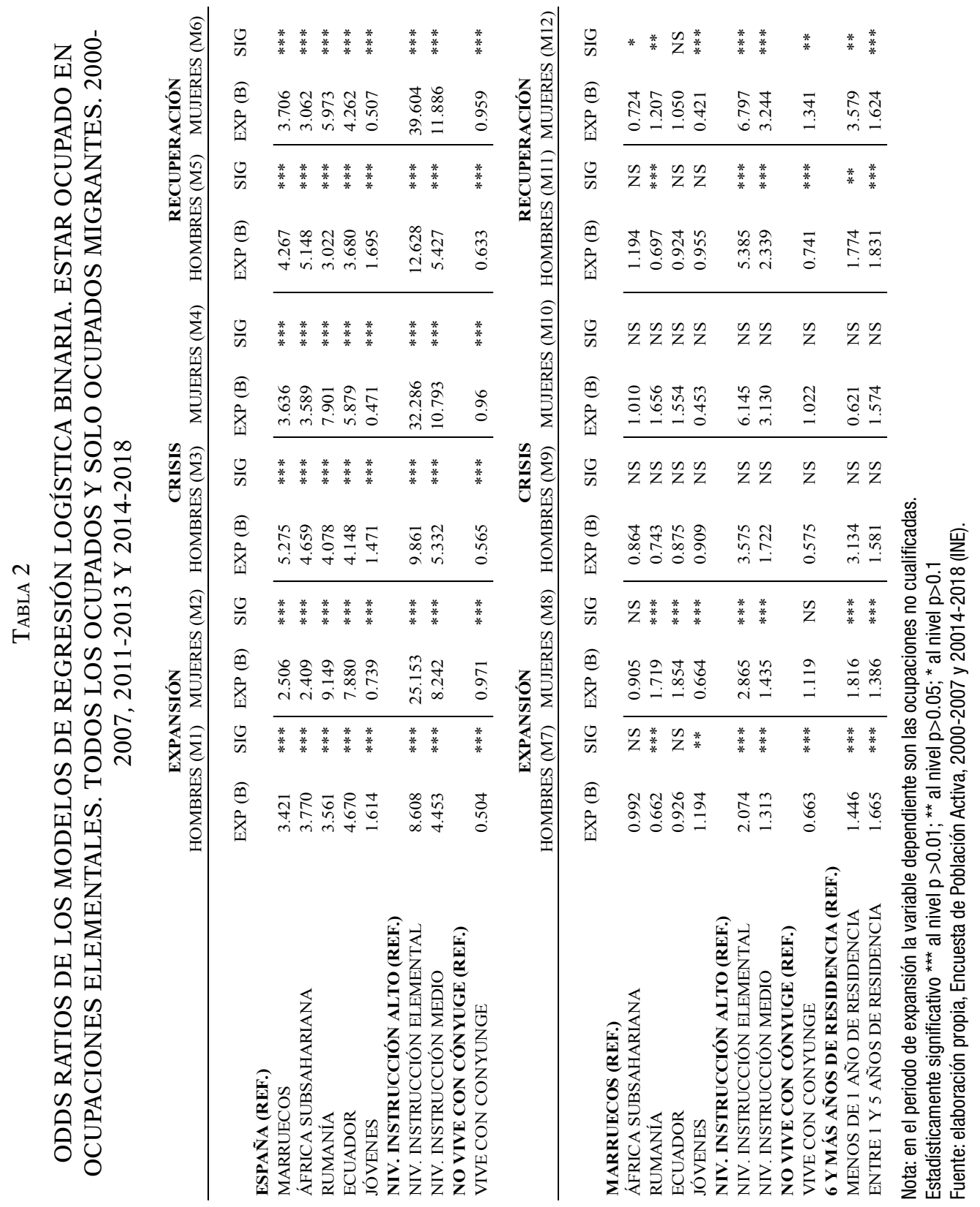


de los ocupados a trabajar en ocupaciones elementales. Los 6 modelos del panel superior (M1-M6) abarcan a todos los grupos, distinguiéndose por sexo, para controlar su efecto, ya que constituye un eje fundamental de segregación ocupacional; y el periodo económico, para evitar las distorsiones que pueda ocasionar la coyuntura económica y la restructuración sectorial a lo largo del tiempo. Recordemos que, para sortear la discontinuidad conceptual de las CNOs, la base de la jerarquía ocupacional en la expansión comprende las ocupaciones no cualificadas y en la crisis (solo referida a los años 2011-2013) y en la recuperación las elementales (véase la metodología).

La instrucción es la variable que toma mayor fuerza en la asociación a trabajar en ocupaciones elementales en los 4 modelos superiores, con mayor intensidad entre las mujeres. Prácticamente el trabajar en ocupaciones elementales se explica por un nivel de instrucción bajo. Ahora bien, no queda anulado el efecto del origen $\mathrm{y}$, de hecho, es la segunda variable explicativa: estandarizando el efecto del resto de variables, todos los grupos de inmigrantes en los dos sexos y en las distintas coyunturas económicas, tienen una propensión mayor que los nativos a trabajar en ocupaciones elementales.

Entre los hombres, en la etapa de expansión (M1 Tabla 2), todos los orígenes triplican la probabilidad de estar empleados en ocupaciones elementales respecto a los nativos, pero son los ecuatorianos, de reciente llegada, los que mayor inclinación registran con relación a los nativos. En la crisis (M3), son los africanos los que muestran los parámetros más elevados, llegando a quintuplicar la suerte de los españoles en trabajar en ocupaciones elementales. En la recuperación (M5 Tabla 2), en cambio, no cambia la pauta y continúan los africanos mostrándose más propensos. Esto ocurre teniendo controlado el efecto de la edad, que en ambos periodos muestra que los jóvenes son los que tienen mayor predisposición, y el de la situación de pareja, que indica una mayor asociación con la ocupación elemental entre los solteros.

Sin embargo, la interacción en los modelos entre el nivel educativo y origen (Figura 4), señala que la distancia entre la propensión a trabajar en ocupaciones elementales de los hombres con niveles de instrucción elementales y medios en relación con los altos es mucho más acusada entre los nativos que en el resto de los grupos en ambos periodos — no se muestra la tabla-. Es decir, el nivel de instrucción 
tiene un efecto más elevado entre los primeros en determinar la suerte de trabajar en ocupaciones elementales que entre los inmigrantes: así en el período de expansión, los de instrucción elemental cuentan con una propensión a trabajar en ocupaciones elementales 10 veces superior entre los nativos; $y$, en cambio, los ecuatorianos de más bajo nivel señalan solo el doble en relación con los de más alto nivel. En el periodo de recuperación se repite la pauta, aunque más exagerada y en el periodo de crisis, el nivel educativo se vuelve prácticamente irrelevante entre los inmigrantes. Estos resultados se alinean a los de otros trabajos (Friedberg, 2000; Basilio et al., 2017) que señalan el escaso valor que adquiere la formación educativa de los inmigrantes y las dificultades de su transferibilidad en términos de ganancia en el mercado de trabajo en el país de destino, especialmente si se ha adquirido fuera de éste (Williams y Baláž, 2005), a esto se añade que su empleo tiende a ser más sensible a la coyuntura (Orrenius y Zavodn, 2010).

FIGURA 4

ODDS RATIO-EXP (B)-DE LA INTERACCIÓN ENTRE ORIGEN (ÁFRICA - MARROQUÍES Y SUBSAHARIANOS-, RUMANÍA, ECUADOR Y ESPAÑA) Y NIVEL DE INSTRUCCIÓN (REF: NIVEL DE INSTRUCCIÓN ALTO) EN TRABAJAR EN OCUPACCIONES ELEMENTALES. OCUPADOS HOMBRES 2000-2007, 2011-2013 Y 2014-2018

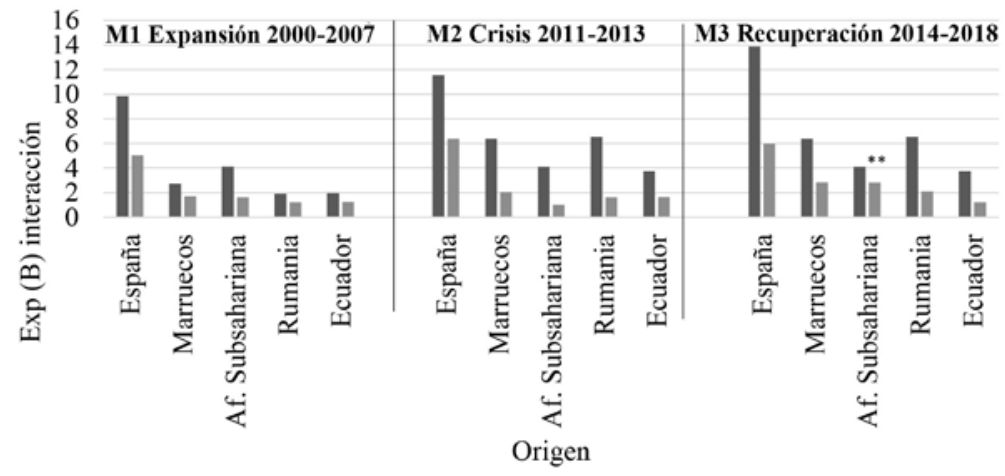

- Nivel instrucción elemental $=$ Nivel instrucción medio

Fuente: elaboración propia, Encuesta de Población Activa, 2000-2007 y 20014-2018 (INE). 
En los modelos masculinos homólogos, realizados solo para los inmigrantes y situando a la población marroquí como grupo de referencia (M7, M9 y M11 Tabla 2) se introduce también el efecto de los años de residencia en España, puesto que cabe pensar que los que más tarde llegan, son candidatos a los peores trabajos. Efectivamente, se observa un efecto negativo de esta variable que apunta, con datos transversales, cierta movilidad ascendente a medida que se lleva más tiempo residiendo en España. La diferencia en este modelo entre marroquíes y ecuatorianos no es significativa, lo que plantea la hipótesis de que una parte de la desventaja de los ecuatorianos, observada en el modelo M1 (Tabla 2), se debiera al menor tiempo de residencia en España (de media, los marroquíes llevaban 8,12 años de residencia frente a 3,72 de los ecuatorianos). Sin embargo, los rumanos sí muestran diferencias significativas respecto a los marroquíes que, tanto en la expansión como en la recuperación, tienen una asociación con trabajos elementales inferior -entre un 30\% y un 34\%-. También los rumanos tienen menor tiempo de residencia en España que los marroquíes (7,11 años en la expansión), aunque si se controla el efecto de la diferencia de años de residencia les beneficia, además de contar con la ventaja de ser trabajadores comunitarios desde 2007.

Las rumanas y ecuatorianas, en relación con las españolas, (M2, M4 y M6 Tabla 2) son las que presentan mayor propensión a estar en ocupaciones elementales en todo el periodo, aunque las diferencias con las africanas parecen reducirse en la recuperación. Introduciendo la interacción entre educación y origen y calculando los respectivos parámetros (Figura 5), entre ellas, todavía se percibe más el efecto diferenciado de la educación entre nativas e inmigrantes en la segregación ocupacional. Entre las nativas, las de educación elemental tienen 30 y 50 veces más inclinación a ocuparse en el nicho último de la jerarquía laboral en el periodo de expansión y recuperación; y, las de nivel medio, también muestran una distancia considerable. Entre las inmigrantes, el tener un nivel de instrucción más o menos elevado no diferencia tanto la suerte de trabajar en ocupaciones elementales. Rumanas y ecuatorianas, registran las menores diferencias de segregación ocupacional en función de la instrucción, lo que probablemente esconda una sobrecualificación en sus ocupaciones (entre las trabajadoras en ocupaciones elementales, las de menor instrucción tienen un peso 38 puntos porcentuales mayor entre las marroquíes que entre las rumanas y 49 puntos más en relación con las ecuatorianas). 
FigURA 5

ODDS RATIO-EXP (B)-DE LA INTERACCIÓN ENTRE ORIGEN (ÁFRICA -MARROQUÍES Y SUBSAHARIANAS-, RUMANÍA, ECUADOR Y ESPAÑA) Y NIVEL DE INSTRUCCIÓN (REF: NIVEL DE INSTRUCCIÓN ALTO) EN TRABAJAR EN OCUPACCIONES ELEMENTALES. OCUPADAS MUJERES 000-2007, 2011-2013 Y 2014-2018

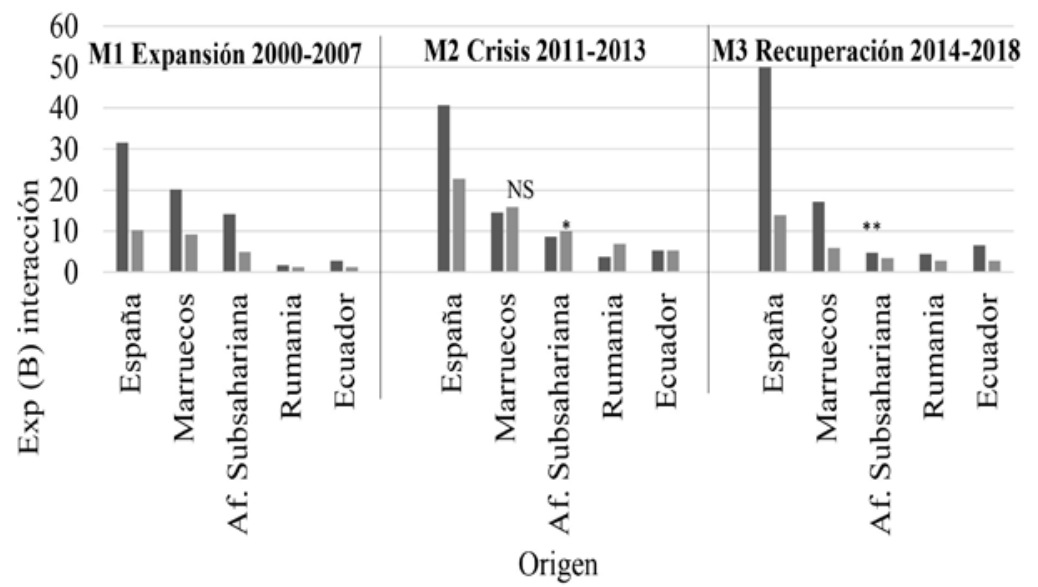

— Nivel instrucción elemental $\quad$ Nivel instrucción medio

Fuente: elaboración propia, Encuesta de Población Activa, 2000-2007 y 20014-2018 (INE).

Cuando se controla el tiempo de residencia para las mujeres (M8, M10 y M12 Tabla 2) y se toma como referencia a la población marroquí, contrariamente al efecto que observábamos entre los hombres, son las rumanas y ecuatorianas las más proclives a la ocupación elemental junto a las subsaharianas. Como veremos, la posición de desventaja de la población africana se vehicula más por las dificultades de inserción laboral, que se traduce en una mayor afectación del paro y, sobre todo, en una mayor precariedad laboral. En cambio, ecuatorianas y rumanas parecen experimentar una desventaja relacionada con cierta sobrecualificación. 


\subsection{Brecha en el paro}

La Tabla 3 muestra los modelos de la propensión al paro de los activos y activas en las tres coyunturas económicas recientes por grupos de edad - jóvenes y adultos- Controlando el efecto del nivel de instrucción y la situación de pareja, los africanos jóvenes (M1, M3 y M5 Tabla 3) resultan más proclives al paro que los nativos, las odds ratios de éstos son mayores en la crisis, pero no desaparecen en la recuperación con una inclinación de un $26 \%$ mayor entre marroquíes que entre nativos, por tanto, es una tendencia continuada en el tiempo. En cambio, ecuatorianos y rumanos no señalan diferencias significativas con los nativos. Entre ellas, y en ese grupo de edad, la bipolarización por origen aún es más acentuada. Pues las propensiones de paro de las africanas con relación a las nativas son significativamente más altas (M2, M4 y M6 Tabla 3) que en el resto de los orígenes e incluso en la recuperación. Mientras que las ecuatorianas jóvenes se sitúan en una posición de ventaja respecto a las nativas siendo las rumanas, solo en el periodo de crisis, las que muestran mayor afectación al desempleo que las españolas, aunque reportan unas odds más bajas que las africanas.

Entre los hombres adultos (M7, M9 y M11 Tabla 3), las odds de los africanos, excepto en el periodo de crisis, que se igualan entre los inmigrantes, siempre son superiores que en el resto llegándose a doblar, durante la recuperación, la predisposición nativa al paro, tanto de marroquíes como de subsaharianos. Ecuatorianos y rumanos, a diferencia de lo que veíamos entre jóvenes, registran mayor tendencia al paro que nativos, aunque con diferencias menores que las señaladas para los africanos respecto a estos últimos y disminuyendo considerablemente en la recuperación.

El paro, excepto en el periodo de crisis, que se iguala entre todos los orígenes, afecta menos a las ecuatorianas adultas que a las nativas. Mientras que las africanas, estandarizando por nivel de estudios y situación de pareja, contraria e invariablemente, presentan mayor inclinación que las últimas. Por su parte, las rumanas, excepto en la expansión, también se ven más perjudicadas que las nativas, pero con unas odds menores que en el caso de africanas. Así pues, en ningún caso, las diferencias de perfiles sociodemográficos en educación y edad de los inmigrantes explican sus diferencias con la posición relativa que tienen con los nativos en relación con el desempleo. 

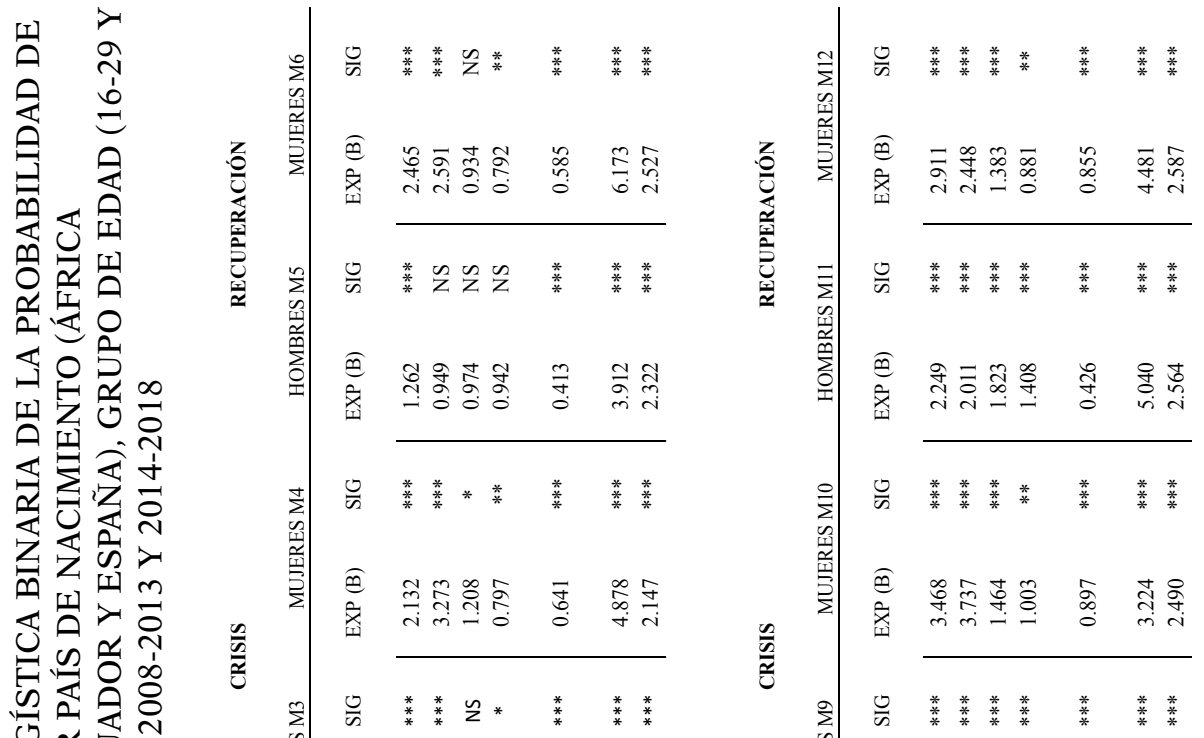

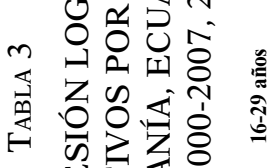

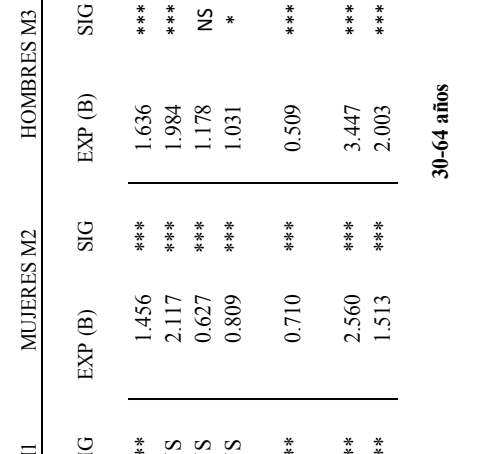

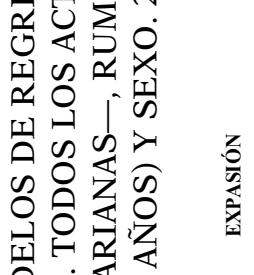

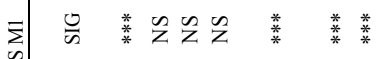

产

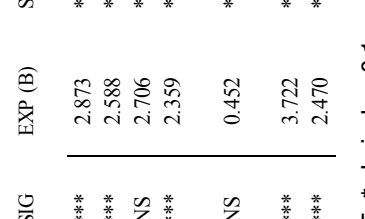

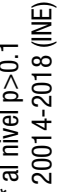

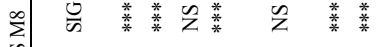
เిิ

䋨

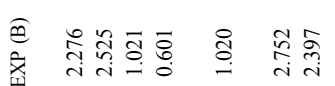

ำ 잉

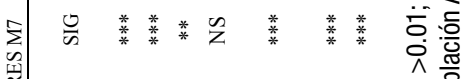

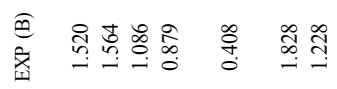

बิ
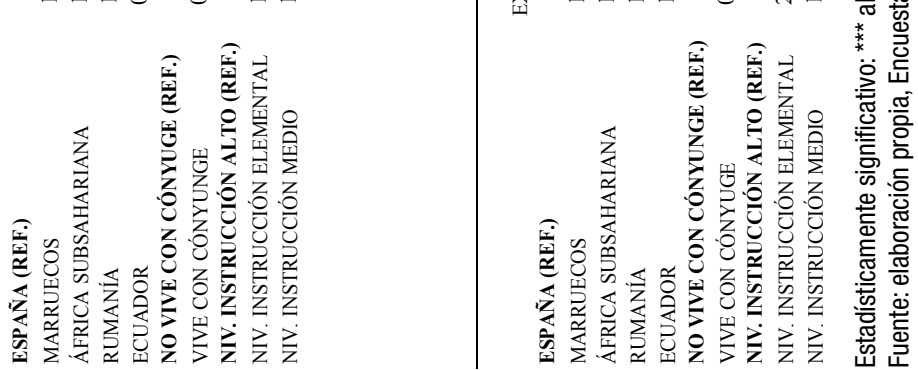
En la Tabla 4 aparecen los modelos logísticos homólogos, donde hemos seleccionado únicamente a la población inmigrante, siendo los marroquíes el grupo de referencia e introduciendo como variable independiente el tiempo de residencia en España. Controlando su efecto negativo, además de la instrucción y la situación de pareja, los rumanos y ecuatorianos tienen una asociación con el paro menor, en todos los periodos, tanto jóvenes (M1, M3 y M5 Tabla 4) como adultos (M7, M9 y M11 Tabla 4), que los marroquíes, sin que la recuperación haya cambiado este patrón. En este periodo y solo para los jóvenes, los subsaharianos también presentan una asociación menor (20\%) con el paro que los marroquíes. En relación con la población marroquí, las diferencias de propensión al paro de ecuatorianos y rumanos entre sí no muestran una pauta clara por sexos y períodos entre los jóvenes, pero sí entre las mujeres adultas: los parámetros de propensión al paro con las mujeres marroquíes son significativa y notablemente más bajos entre ecuatorianas que rumanas. Debemos suponer que una de las razones, aunque pueda no ser la única, es que gran parte de los trabajos desempeñados por las mujeres en las ocupaciones elementales tienen que ver con el servicio doméstico y personales, y el idioma y mayor cercanía cultural de las ecuatorianas, puede presuponerse un capital humano especialmente valioso en estos dominios.

Las mujeres muestran las mismas tendencias atemporales por origen, aunque más descomedidas, especialmente, entre las adultas: si consideramos la inversa de las odds, las marroquíes de 30 a 64 años señalan una inclinación al paro 3,4 veces superior al de las ecuatorianas $(1 / 0.296)$ y 2,6 veces al de las rumanas durante la recuperación.

Cuando se introduce el tiempo de residencia, el nivel de instrucción entre los inmigrantes no muestra relevancia estadística en determinar la posibilidad de paro entre la población masculina y solo lo hace entre las mujeres jóvenes. Sin embargo, en la crisis, entre los hombres y mujeres jóvenes y adultas sí tiene efecto, mientras que entre los adultos no. En la recuperación retoma la significación, pero no anula en ningún periodo la mejor situación relativa en hombres y mujeres de la población rumana y ecuatoriana respecto a la marroquí, con parámetros siempre inferiores a éstos. La introducción de las variables mediante el método paso a paso destaca el origen como una de las variables explicativas más relevantes para entender la propensión al paro, por delante de la 


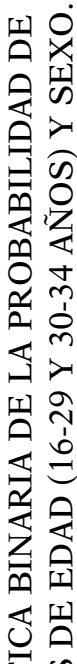

$\infty$

⿻

零

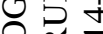

언유

근궁

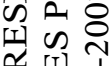

민됭

핀융

II

I

is

象

동ำ

n

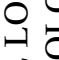

피 Us

品

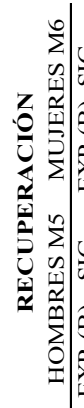

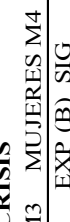

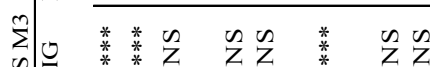

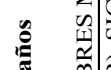

तิ่

$\Sigma$

\begin{tabular}{c}
$\sum_{2}$ \\
II \\
\hline
\end{tabular}

z

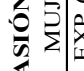

站

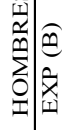

党|

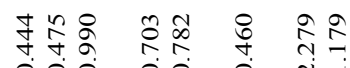
००० 00 0. तु

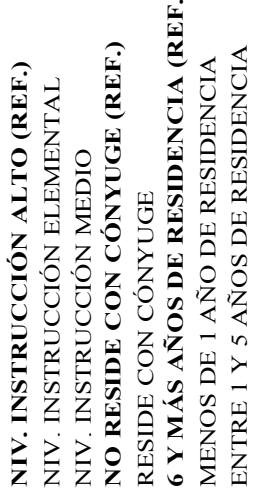

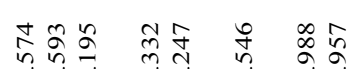

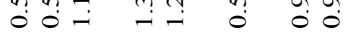

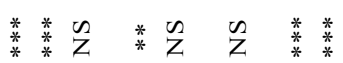

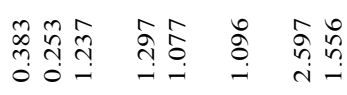

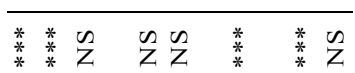

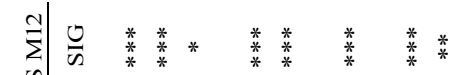

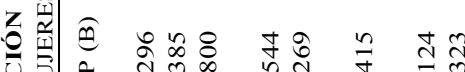
तु

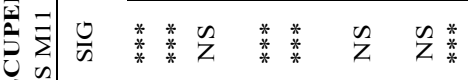

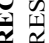

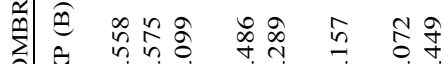

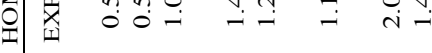

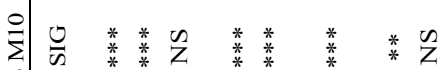

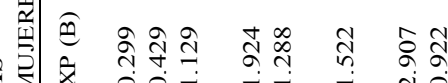

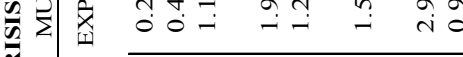

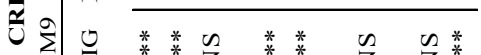

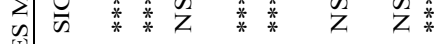

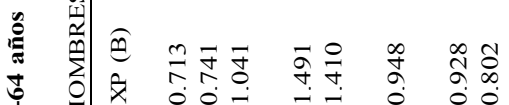
家 $00-1,-0$. 00

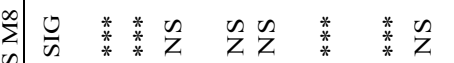

离

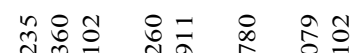

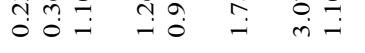
$*$ ชั 수

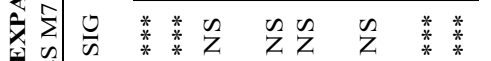
政

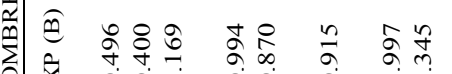

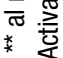

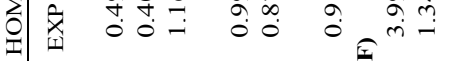
ㅎ. 욤

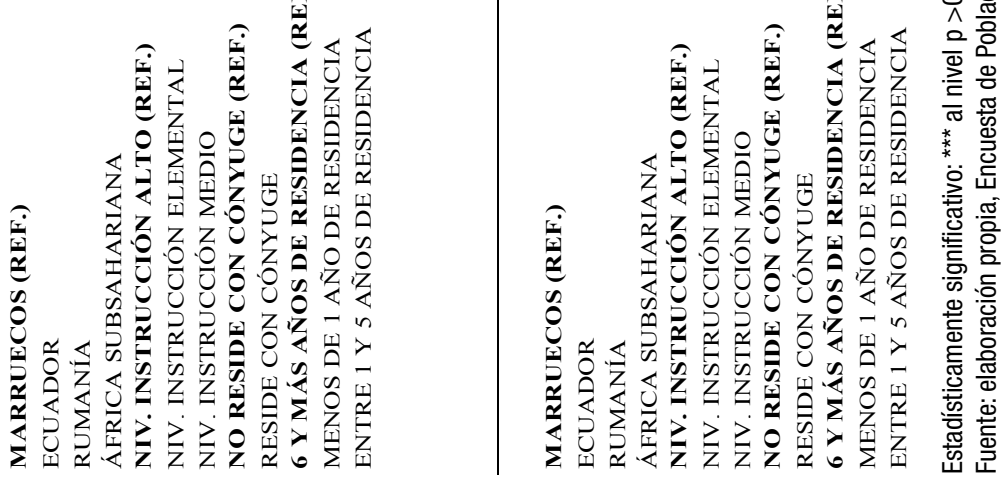


instrucción y los años de residencia. La duración de la residencia pierde fuerza explicativa en el periodo de crisis y recuperación, excepto en las mujeres adultas en el último periodo, seguramente ligado a que la mayoría de los flujos de todos los orígenes ya habían superado el período crítico de los primeros asentamientos.

\subsection{Brecha de la precariedad por origen}

Los 4 modelos logísticos binarios que aparecen en la Tabla 5 hacen referencia exclusivamente a la recuperación, analizando el efecto de las variables independientes sobre la precariedad —entendida como el trabajar con contrato temporal; o más horas que la media habitual de la categoría ocupacional más una desviación estándar y querer trabajar menos horas; o a la inversa, trabajar menos horas que la media de dicha categoría menos una desviación estándar y querer trabajar más horas-. De este modo para cada individuo, se comparan las características del empleo individual con las del empleo de su categoría (distinguiendo 17) y sexo. Los modelos 1 y 2 se refieren a todos los grupos poblacionales (Tabla 5) y el 3 y 4 (Tabla 5), solo a los inmigrantes.

Introduciendo las variables paso a paso, en ambos sexos (M1 y M2 Tabla 5), como señalan las teorías de la segmentación laboral, la edad y la categoría profesional son los principales determinantes de la precariedad aunque la categoría ocupacional adquiere mayor fuerza discriminatoria entre los hombres y la edad entre las mujeres: ésta es 5 veces mayor entre aquellos que trabajan en ocupaciones elementales que entre la categoría profesional más alta; entre las mujeres - las jóvenes cuadriplican la propensión de las adultas. Sin embargo, el efecto neto del origen no desaparece, ya que casi todos los migrantes doblan las odds de los nativos, aunque son, de nuevo, los marroquíes los más proclives a la precariedad. Y entre ellas, son las africanas las que despuntan más las diferencias con las nativas.

En los modelos M3 y M4 (Tabla 5), específicos para los inmigrantes, se ha introducido el tiempo de residencia como variable independiente. Encontramos que los años de residencia tienen una relación inversa con la precariedad laboral de los inmigrantes, pero condiciona menos que el origen. El efecto negativo de la variable instrucción y residencia con el cónyuge es el mismo que en los modelos precedentes. Como en el paro, son los marroquíes los que 
TABLA 5

ODDS RATIOS DE LOS MODELOS DE REGRESIÓN LOGÍSTICA BINARIA DE LA PROBABILIDAD DE ESTAR EN PRECARIEDAD INTRASECTOR. TODOS LOS OCUPADOS Y SOLO OCUPADOS MIGRANTES POR PAÍS DE NACIMIENTO (ÁFRICA -MARROQUÍES Y SUBSAHARIANOS-, RUMANÍA, ECUADOR Y ESPAÑA), GRUPOS DE EDAD (16-29 Y 30-34 AÑOS) Y SEXO 2014-2018

\section{RECUPERACIÓN}

\begin{tabular}{lcc|cc} 
& HOMBRES M1 & \multicolumn{1}{c}{ MUJERES M2 } \\
\hline ESPANA (REF.) & EXP (B) & SIG & EXP (B) & SIG \\
MARRUECOS & & & & \\
ÁFRICA SUBSAHARIANA & 2.63 & $* * *$ & 1.65 & $* * *$ \\
RUMANÍA & 1.78 & $* * *$ & 1.80 & $* * *$ \\
ECUADOR & 1.78 & $* * *$ & 1.25 & $* * *$ \\
EDAD 30-64 AÑOS (REF.) & 1.99 & $* * *$ & 1.13 & $* * *$ \\
EDAD 16-29 AÑOS & & & & \\
GEREN, PROF; TÉCN;OFICINA (REF.) & 3.90 & $* * *$ & 4.50 & $* * *$ \\
TRABAJADORES SERVICIOS & 1.21 & $* * *$ & 1.33 & $* * *$ \\
TRABAJADORES CUALIFICA IND y AGR & 1.73 & $* * *$ & 1.39 & $* * *$ \\
OCUPACIONES ELEMENTALES & 5.08 & $* * *$ & 2.53 & $* * *$ \\
NO RESIDE CON CÓNYUGE (REF.) & & & & \\
RESIDE CON CÓNYUGE & 0.57 & $* * *$ & 0.68 & $* * *$
\end{tabular}

RECUPERACIÓN

\begin{tabular}{lcc|cc} 
& HOMBRES M1 & \multicolumn{3}{c}{ MUJERES M2 } \\
\hline MARRUECOS (REF.) & EXP (B) & SIG & EXP (B) & SIG \\
ÁFRICA SUBSAHARIANA & & & & \\
RUMANÍA & 0.69 & $* * *$ & 1.06 & $* * *$ \\
ECUADOR & 0.67 & $* * *$ & 0.74 & $* * *$ \\
EDAD 30-64 AÑ OS (REF.) & 0.80 & $* * *$ & 0.72 & $* * *$ \\
EDAD 16-29 AÑOS & & & & \\
GEREN, PROF; TÉCN;OFICINA (REF.) & 1.78 & $* * *$ & 2.74 & $* * *$ \\
TRABAJADORES SERVICIOS & 1.17 & $* * *$ & 1.65 & $* * *$ \\
TRABAJADORES CUALIFICA IND y AGR & 2.26 & NS & 2.14 & NS \\
OCUPACIONES ELEMENTALES & 5.96 & $* * *$ & 2.85 & $* * *$ \\
NO RESIDE CON CÓNYUGE (REF.) & & & & \\
RESIDE CON CÓNYUGE & 0.62 & $* * *$ & 1.05 & $* * *$ \\
6 Y MÁS AÑ OS DE RESIDENCIA (REF.) & & & & \\
MENOS DE 1 AÑO DE RESIDENCIA & 2.80 & $* * *$ & 3.29 & $* * *$ \\
ENTRE 1 Y 5 AÑOS DE RESIDENCIA & 1.50 & $* * *$ & 1.18 & $* * *$
\end{tabular}

Estadísticamente significativo: ${ }^{* \star}$ al nivel $p>0.01 ;{ }^{* \star}$ al nivel $p>0.05 ;{ }^{*}$ al nivel $p>0.1$

Fuente: elaboración propia, Encuesta de Población Activa 2014-2018 (INE). 
presentan una posición relativa más desaventajada: la tendencia a la precariedad es en ellos un $45 \%$ más elevada que entre los subsaharianos, un $49 \%$ mayor que en rumanos y un $24 \%$ por encima de ecuatorianos (inversas de las odds); entre ellas, ecuatorianas y rumanas respectivamente presentan en torno a un $27 \%$ menos de propensión a la precariedad laboral.

\subsection{Brecha en la actividad femenina}

Como hemos visto en el descriptivo, el incremento de las tasas de actividad de las mujeres africanas a partir de la crisis económica y su mantenimiento durante la recuperación es un comportamiento singular. Para analizar si este aumento se produce a merced de la erosión del modelo tradicional de género de división de roles, se presenta en la Figura 6 el porcentaje por encima o por debajo de la propensión a la actividad de las mujeres con cónyuge no ocupado y ocupado en comparación a las no unidas. Dichos porcentajes han sido calculados a partir de un modelo de regresión binaria y han sido estandarizados por dos variables: edad y nivel de instrucción.

Las menores diferencias de propensión a la actividad en función de la situación familiar se observan entre las mujeres ecuatorianas y rumanas; y las mayores, entre marroquíes y españolas. La propensión de las unidas, en general, de marroquíes y españolas es menor que si no se está unida: entre las primeras, las que tienen cónyuge no ocupado presentan una propensión 70\% inferior que las no unidas a la participación laboral; cuando se tiene un cónyuge ocupado, la distancia incrementa, siendo la de éstas un 76\% menor que las no unidas; los porcentajes correspondientes de las españolas son menores en un 56\% y $72 \%$, respectivamente. En la crisis y recuperación, la propensión a la actividad de las marroquíes unidas sigue por debajo de las no unidas, aunque se muestra mayor diferencia en función de si el cónyuge está ocupado o no, con una reducción de la distancia con las no unidas superior cuando el cónyuge no está ocupado: en el periodo de expansión, las que tienen cónyuge no ocupado ostentan porcentajes un $41 \%$ menores que las unidas y en la recuperación de un 15\% inferior. 
Figura 6

\section{PROPENSIÓN A LA ACTIVIDAD DE LAS MUJERES CON CÓNYUGE NO OCUPADO Y OCUPADO EN RELACIÓN CON LAS NO UNIDAS (EN \% POR ENCIMA O POR DEBAJO) SEGÚN PAÍS DE NACIMIENTO (ÁFRICA MARROQUÍES Y SUBSAHARIANOS-, RUMANÍA, ECUADOR Y ESPAÑA) Y PERÍODO}

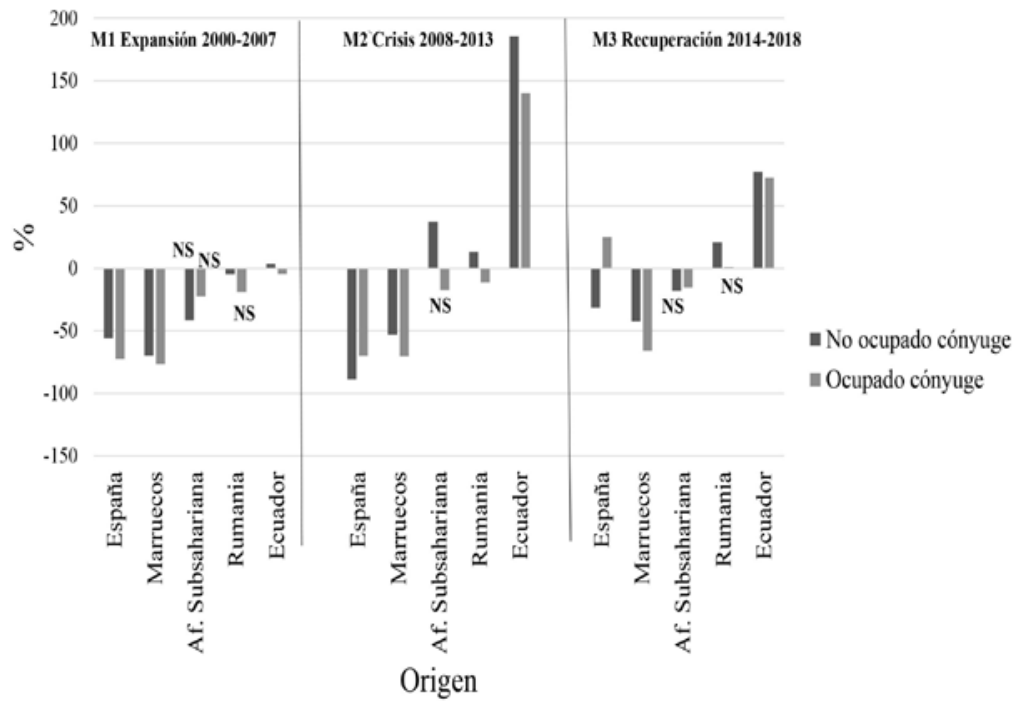

*NS: no significativa

Fuente: elaboración propia, Encuesta de Población Activa 2000-2018.

Entre las ecuatorianas, la crisis incrementa mucho la distancia por situación familiar a favor de las unidas en relación con las no unidas, especialmente de las que no tienen el cónyuge ocupado. En la recuperación, se reduce la diferencia en función de si el cónyuge está o no ocupado y se sigue manteniendo entre las ecuatorianas una mayor inclinación a la participación laboral de las unidas. Las españolas unidas también disminuyen en la recuperación las diferencias con las no unidas, aventajando incluso las que tienen cónyuge ocupado a las no unidas en su asociación con la participación laboral. Las rumanas en los tres periodos muestran pocas diferencias de participación laboral respecto a la situación familiar. En conclusión, existen pocos cambios en las disparidades de propensión a la participación laboral 
entre las marroquís por situación familiar, aunque se observe una reducción de ésta entre unidas y no unidas y especialmente entre las que tienen el cónyuge no ocupado.

\section{CONCLUSIONES}

Recordemos que el propósito de este ejercicio era responder a tres preguntas: si la causa de la situación peor de los africanos en el mercado laboral podía achacarse al nivel de instrucción, si la causa era el tipo de ocupación, y, por último, específicamente para las mujeres, si estábamos asistiendo a un cambio en el patrón generacional de la actividad. Todo ello considerado siempre desde una perspectiva de género, y desde la generacional, al confrontar jóvenes y adultos.

El nivel de instrucción es la variable fundamental para explicar la segregación ocupacional de hombres y mujeres en el mercado laboral en el periodo de expansión y de recuperación, pero no anula el efecto del origen como eje de segmentación, convirtiéndose en la segunda variable con mayor poder predictivo, dividiendo la suerte de caer en ocupaciones elementales entre autóctonos e inmigrantes en los dos periodos y en ambos sexos, siendo la de los últimos mucho mayor, aun teniendo controlado también el efecto del sexo y las diferencias de perfiles por edad. Los africanos no muestran una propensión a trabajar en ocupaciones elementales significativamente mayor que el resto de los inmigrantes, pero sí señalan, al igual que los demás, un efecto menor de la instrucción respecto a los nativos en la determinación de quiénes van a ser los candidatos para ocupar los trabajos elementales. Por tanto, están penalizados porque tienen un nivel educativo más bajo que el resto y porque el rendimiento de un nivel educativo alto es menor que entre los nativos. Eso podría desembocar en un techo más bajo de la movilidad social que en los otros orígenes, o si se quiere que, para los africanos, resultase más difícil salir de ese nicho laboral (el suelo pegajoso).

El nivel de instrucción no explica totalmente la posición de desventaja de la población africana con relación al paro frente a la población nativa y al resto de inmigrantes. Incluso en el periodo de expansión económica, las diferencias educativas no resultan significativas para dar cuenta de la mayor propensión al paro de la población marroquí en relación con los otros orígenes. Durante 
la crisis y recuperación, aunque tiene un efecto significativo, no anula el de las diferencias por origen, que castigan a la población africana, y con más contundencia estadística a la marroquí, con el paro en mayor medida que a los otros orígenes. Por su carácter continuado - en todos los periodos y sexos, esta desventaja podría configurarse como una característica estructural del mercado laboral, cronificándose y multiplicando su efecto. No es entonces el nivel de instrucción la respuesta única de esta situación estructural.

El rol del capital humano no parece ser tan relevante cuando se analizan las diferencias entre africanos y otros grupos de migrantes. Claro está que estos efectos han sido medidos mediante el máximo nivel de estudios alcanzado y algunas investigaciones han revelado el mayor impacto que el capital humano no formal ligado a la experiencia migratoria — confianza, habilidades interpersonales, lengua-, tiene en los resultados económicos de los migrantes (Williams y Baláž, 2005) así como la distinta valoración que, además, asume el capital formal en destino en función del origen de procedencia del migrante y del lugar donde se ha adquirido la formación (Basilio, et al., 2017).

En relación con el efecto diferencial de la educación sobre la propensión a estar en paro, nuestros resultados van en la dirección de lo señalado por Cebolla-Boado y colaboradores (2015) con relación a su menor impacto diferenciador en la coyuntura de expansión —de menor competencia, y entre migrantes, pero matizándolos. Esta relación es mucho menos clara entre jóvenes y entre mujeres. Entre los jóvenes, probablemente el ajuste entre nivel educativo alcanzado y el tipo de ocupación que se busca desempeñar sea menor y ello probablemente se traducirá en un menor efecto de la educación formal en determinar las diferencias en las propensiones al paro. Por otro lado, los nichos ocupacionales de las mujeres están muy cercanos a las ocupaciones y servicios de proximidad, sobre todo entre migrantes, donde quizás la credencial del capital humano no formal adquiere más valor.

¿Qué sucede con el tipo de ocupación? El nicho ocupacional, como se ha visto, no es la única explicación de la mayor precariedad de la población marroquí en el mercado de trabajo, comparando las condiciones de empleo de cada individuo —en términos de contrato indefinido y de horas de trabajo habitual de su sexo por encima o por debajo de la media de su categoría ocupacional así como su disconformidad en ello-, controlando las diferencias poblacionales 
por edad, sector de ocupación y años de residencia en España, ser africano, y con más rotundidad, ser marroquí, penaliza con mayor precariedad laboral. El tiempo de residencia tampoco ofrece más garantías de mejor posicionamiento frente al paro, aun teniendo una relación negativa, no anula el efecto del origen, aunque ese tiempo presente mayor fuerza explicativa en el periodo de expansión que en el de crisis. Dicho de otro modo: el tiempo de residencia, precisamente para la población inmigrada con más solera en España, no garantiza una mejora de su situación, no sólo frente al paro sino tampoco en relación con la precariedad.

Nuestros resultados se alinean con los de otros trabajos que señalan que la posición de desventaja de determinados grupos de inmigrantes comprende una variación inexplicada o lo que es lo mismo, un efecto neto de origen del inmigrante, que presumiblemente respondería a prácticas discriminatorias, aun admitiendo que una parte de esta posición se avale también por efectos composicionales relacionados con los nichos ocupacionales que ocupan, o incluso por diferencias en el capital humano (Cebolla-Boado et al., 2015; Mooi-Reci y Muñoz-Comet, 2016).

Por último, en cuanto a la adición de las mujeres africanas a la actividad laboral durante la crisis y recuperación, hemos encontrado que también las nativas españolas siguen esa pauta, siendo perceptible entre éstas, igualmente, un cambio de patrón generacional. Diferenciándose ambas de ecuatorianas y rumanas, seleccionadas como migrantes precisamente por su actividad frente a las africanas que llegaban como cónyuges o hijas reagrupadas, más relacionadas con trabajos reproductivos que con la inserción en el mercado. La crisis económica, ha hecho declararse activas a mujeres africanas de generaciones mayores que de otro modo no lo hubieran hecho - especialmente entre las marroquíes-, en un claro efecto adicional, pudiendo la persistencia de la precariedad entre este colectivo explicar también la continuidad de esa pauta. El aumento de la declaración de la actividad entre las más jóvenes, así mismo está mediatizado por la crisis. Aunque ésta sea el detonante del cambio, su continuidad en el tiempo podría propiciar una transformación en los roles tradicionales de género que conforman sus pautas de participación laboral. Sin embargo, hemos visto que, por ahora, la participación en el mercado laboral de las marroquíes sigue estando muy condicionada por la situación marital, señalando unas diferencias significativas de participación laboral en función de 
si están unidas y de si el cónyuge está ocupado — con una actividad laboral significativamente menor en este caso, lo que traduce un patrón de género muy alejado del de las ecuatorianas - con una participación mayor entre las unidas y menores diferencias en función de la ocupación del cónyuge, excepto en la crisis-; y en esta distancia con las ecuatorianas, le acompañan también las nativas.

Por todo ello, y tras haber logrado una aproximación a la inmigración, en general, y de los africanos, en particular, en el mercado laboral español, es prioritario continuar con la investigación añadiendo otros ejes y variables, incluso de carácter extrademográfico, que logren explicar el porqué de la precariedad de su situación. Debido a la imposibilidad con la que nos hemos encontrado de explicar, mediante las variables clásicas, a qué se debe este empeoramiento y esta distinción según el país de nacimiento.

\section{BIBLIOGRAFÍA}

Aja, E., Arango, J. y Oliver, J. (2013). Crisis, mercado de trabajo y cambiantes tendencias migratorias. En E. Aja, J. Arango y J. O. Alonso (Eds.), Inmigración y crisis: Entre la continuidad y el cambio. Anuario de inmigración en España 2012 (pp. 12-24). Barcelona: CIDOB.

Amuedo Dorantes, C. y De la Rica, S. (2007). Labour Market Assimilation of Recent Immigrants in Spain. British journal of industrial relations, 45(2), 257-284.

Aparicio Gómez, R. y Tornos Cubillos, A. (2006). Hijos de inmigrantes que se hacen adultos: marroquies, dominicanos, peruanos (Documentos del Observatorio Permanente de la Inmigración, n.8). Madrid: Ministerio de Trabajo y Asuntos Sociales y Observatorio Permanente de la Inmigración.

Basilio, L., Bauer, T. K. y Kramer, A. (2017). Transferability of Human Capital and Immigrant Assimilation: An analysis for Germany. Labour, 31(3), 245-264.

Becker, G. (1964). Human Capital: A Theoretical and Empirical Analysis with Special Reference to Education. Londres: National Bureau of Economic Research.

Berriane, M. (1996). Las regiones tradicionales de la emigración magrebí. En B. López García (Ed.), Atlas de la inmigración magrebi en España (pp. 5153). Madrid: UAM ediciones.

Berriane, M. (2004). Regiones institucionales y focos migratorios. En B. López García y M. Berriane (Eds.), Atlas de la inmigración marroquí en Espa$\tilde{n} a$ (pp. 125-128). Madrid: UAM ediciones. 
Boyd, M. (1984). At a Disadvantage: The Occupational Attainment of ForeignBorn Women in Canada. International Migration, 18(4), 1091-1119. https:// doi.org/https://doi.org/10.1177/019791838401800410

Cachón Rodríguez, L. (2002). La formación de la «España inmigrante»: Mercado y ciudadanía. REIS. Revista Española de Investigaciones Sociológicas, (97), 95-126.

Cachón Rodríguez, L. (2003). Inmigración y segmentación de los mercados de trabajo en España (Documento de trabajo. Serie Sociología S2003/02). Sevilla: Centro de Estudios Andaluces.

Cachón Rodríguez, L. (2009). La España inmigrante: Marco discriminatorio, mercado de trabajo y política de integración. Barcelona: Anthropos.

Carrasco, R., Jimeno, J. F. y Ortega, A. C. (2008). The effect of immigration on the labor market performance of native-born workers: some evidence for Spain. Journal of Population Economics, 21(3), 627-648.

Carrasco Carpio, C. y García-Serrano, C. (2015). Efectos de la crisis en la estructura ocupacional y la biografía laboral de la población inmigrante. Migraciones, 37, 75-96.

Carvajal, M. I. y Pumares, P. (2004). Los trabajadores marroquíes en alta laboral en la Seguridad Social. En B. López García y M. Berriane (Eds.), Atlas de la inmigración marroquí en España (pp. 402-407). Madrid: Ministerio de Trabajo y Asuntos Sociales.

Cebolla-Boado, H., Miyar-Busto, M. y Muñoz-Comet, J. (2015). Is the Spanish Recession Increasing Inequality? Male Migrant-Native Differences in Educational Returns Against Unemployment. Journal of Ethnic and Migration Studies, 41(5), 710-728.

Chiswick, B. R. (1978). The Effect of Americanization on the Earnings of Foreign-Born Men. Journal of Political Economy, 86(5).

Chiswick, B. R. (1979). The Economic Progress of Immigrants : Some Apparently Universal Patterns. Contemporary economic problems, 357-399.

Chiswick, B. R., Lee, Y. y Miller, P. (2005). A Longitudinal Analysis of Immigrant Occupational Mobility: A Test of the Immigrant Assimilation Hypothesis. International Migration Review, 39(2), 332-353. https://doi.org/ http://dx.doi.org/10.1111/j.1747-7379.2005.tb00269.x

Chiswick, B. R. y Miller, P. (2009). The International Transferability of Immigrants' Human Capital. Economics of Education Review, 28(2), 162-169.

Colectivo Ioé. (2012). Crisis e inmigración marroquí en España. 2007-2011, 27.

Doeringer, P. B. y Piore, M. J. (1971). Internal Labor Markets and Manpower Analysis. Lexington: DC Heath and Co.

Congregado, E., Golpe, A. A. y Van Stel, A. (2011). Exploring the big jump in the Spanish unemployment rate: Evidence on an «added-worker» effect. Economic Modelling, 28(3), 1099-1105. https://doi.org/10.1016/j.econ$\bmod .2010 .11 .018$

Cuadrado Roura, J. R. y Iglesias Fernández, C. (2003). Cambio sectorial y desempleo en España: Un análisis de la relación entre terciarización, cambio 
cualificativo y movilidad laboral en España. (Fundación BBVA, Ed.). Bilbao.

Fernández-Huerga, E. (2010). La teoría de la segmentación del mercado de trabajo: Enfoques, situación actual y perspectivas de futuro. Investigación Economica, 69(273), 115-150. https://doi.org/10.22201/ fe.01851667p.2010.273.24253

Fernández-Macías, E., Grande, R., Del Rey, A. y Antón, J. I. (2015). Employment and Occupational Mobility among Immigrants Recently. The Spanish Case 1997-2007. Population Research and Policy Review, 34(2), 243-277.

Fernández, C. y Ortega, C. (2008). Labor market assimilation of immigrants in Spain: Employment at the expense of bad job-matches? Spanish Economic Review (10),83-107 https://doi.org/10.1007/s10108-007-9032-4

Fox, J., Moroşanu, L. y Szilassy, E. (2012). The Racialization of the New European Migration to the UK. Sociology, 46(4), 680-695. https://doi.org/ https://doi.org/10.1177/0038038511425558

Friedberg R (2000) You Can't Take it with You? Immigrant Assimilation and the Portability of Human Capital: Evidence from Israel. Journalof Labor Economics, 18(2),221-251.

Garson, J. P. y Dumont, J. C. (2009). Crisis económica y migraciones. Bases para la reflexión. En E. Aja, J. Arango y J. Oliver Alonso (Eds.), La inmigración en tiempos de crisis. Anuario de la inmigración en España (pp. 45-51). Barcelona: CIDOB. https://www.raco.cat/index.php/AnuarioCIDOBInmigracion/article/view/355621

Gil, F. y Domingo, A. (2008). Latinoamericanos en el mercado de trabajo español, 2000-2005. Papeles de Población, (55), 145-172.

Grande, R., Paniagua, T. y del Rey, A. (2016). Inmigración y mercado de trabajo en España : Del boom a la Gran Recesión. Panorama Social, (23), 125-139.

Hagan, J. M. (2004). Contextualizing Immigrant Labor Market Incorporation. Work and Occupations, 31(4), 407-423. https://doi. org/10.1177/0730888404268921

Hall, M. y Farkas, G. (2008). Does Human Capital Raise Earnings for Immigrants in the Low-Skill Labor Market?.Demography, 45(3), 619-639.

Herranz Gómez, Y. (2000). Inmigración e incorporación laboral. Migraciones, (8), 127-164.

Humphrey, D. (1940). Alleged «Additional Workers» in the Measurement of Unemployment. Journal of Economic Studies, 48, 412-419.

Iglesias, J., Botella, T., Rua, A., Mielgo, C. y Caro, R. (2015). Estudio sobre la situación laboral de la mujer inmigrante en España. Madrid:Organización internacional para las migraciones (OIM) e Insitituto Universitario de Estudios sobre Migraciones.

Janta, H., Jephcote, C., Williams, A. M. y Li, G. (2019). Returned migrants acquisition of competences: The contingencies of space and time. 
La brecha africana: desigualdad laboral de la inmigración marroqui y subsahariana... 219

Journal of Ethnic and Migration Studies, 1-18. https://doi.org/10.1080/1 369183X.2019.1679408

Laparra, M. y Pérez Eransus, B. (2012). Crisis y fractura social en Europa. Causas y efectos en España (Colección Estudios Sociales, n. 35). Barcelona.

Massey, D., Alarcón, R., Durand, J. y González, H. (1987). Return to Aztlan: The Social Process of International Migration from Western Mexico. Berkeley: University of California Press.

Miguélez, F. y López-Roldán, P. (2014). Crisis, empleo e inmigración en España. Un análisis de las trayectorias laborales. Barcelona: La Caixa.

Miyar-Busto, M. y Muñoz-Comet, J. (2018). Inmigrantes sucesivos en el mercado de trabajo español. Trayectorias migratorias y capital de movilidad. Revista Internacional de Sociología, 76(1), e088. https://doi.org/https:// doi.org/10.3989/ris.2018.76.1.15.192

Molpeceres Álvarez, L. (2012). Situación laboral de las mujeres inmigrantes en España. Cuadernos de Relaciones Laborales, 30(1), 91-113. https://doi. org/10.5209/rev_crla.2012.v30.n1.39116

Montero, J. M. y Regil,A. (2015). La tasa de actividad en España: resistenca cíclica, determinantes y perspectivas futuras, Documentos ocasionales del Banco de España,1502, 8-42.

Mooi-Reci, I. y Muñoz-Comet, J. (2016). The Great Recession and the Immigrant-Native Gap in Job Loss in the Spanish Labour Market. European Sociological Review, 32(6), 730-751.

Muñoz Comet, J. (2012). Evolución del empleo y del paro de las mujeres inmigrantes en el mercado de trabajo español. El impacto de la actual crisis económica. Cuadernos de Relaciones Laborales, 30(1), 115-137. https://doi.org/http://dx.doi.org.10.5209/rev_CRLA.2012.v30.n1.39117

Muñoz-Comet, J. (2013). La salida del desempleo de extranjeros y españoles. Efectos del contexto económico. REIS: Revista Española de Investigaciones Sociológicas, 142, 45-68.

Noel, D. L. (1968). A Theory of the Origin of Ethnic Stratification. Social Problems, 16(2), 157-172. https://doi.org/10.2307/800001

Orrenius, P. y Zavodny, M. (2010). Immigrant employment outcomes over the business cycle. IZA Discussion Paper No. 5354. Bonn: IZA.

Piore, M. (1969). On-the-job Training in Dual Labor Markets. En A. Weber, F. Cassell y G. Woodrow (Eds.), Public-private Manpower Policies (pp. 101132). Madison: Industrial Relations Research Association.

Piore, M. (1975). Notes for a Theory of Labor Market Stratification. En R. Edwards, M. Reich y D. Gordon (Eds.), Labor Market Segmentation (pp. 125-150). Lexington: D.C. Heath and Co.

Piore, M. J. (1980a). Dualism as a Response to Flux and Uncertainty. En M. J. Piore y S. Berger (Eds.), Dualism and Discontinuity in Industrial Societies (pp. 23-54). Cambridge: Cambridge University Press. 
Piore, M. J. (1980b). The Technological Foundations of Dualism and Discontinuity. En M. J. Piore y S. Berger (Eds.), Dualism and Discontinuity in Industrial Societies (pp. 55-81). Cambridge: Cambridge University Press.

Posso, C. M. (2010). Calildad del empleo y segmentación laboral: Un análisis para el mercado laboral colombiano 2001-2006. Desarrollo y sociedad, $65,191-234$.

Prieto-Rodríguez, J. y Rodríguez-Gutiérrez, C. (2000). The added worker effect in the Spanish case. Applied Economics, 32(15), 1917-1925. https:// doi.org/10.1080/00036840050155841

Pumares Fernández, P., García Coll, A. y Asensio Hita, Á. (2006). La movilidad laboral y geográfica de la población extranjera en España. Madrid: MTAS.

Raijman, R. y Semyonov, M. (1997). Gender, Ethnicity and Immigration: Double Disadvantage and Triple Disadvantage among Immigrant Women in the Israeli Labor Market. Gender \& Society, 11(1), 108-125. https://doi.org/10.1177/089124397011001007

Recio, A. y Banyuls, J. (2011). Crisis y modelos nacionales de empleo: La experiencia de diez países europeos en la crisis. Revista de Economía Crítica, (11), 173-184.

Ribas Mateos, N. (2005). La feminización de las migraciones desde una perspectiva filipina. CIDOB d'Afers Internacionals, 68, 67-87.

Simón, H., Ramos, R. y Sanromá, E. (2014). Inmigrant Occupational Mobility: Longitudinal Evidence from Spain. European Journal of Population, 30, 223-255.

Sjaastad, L. A. (1962). The Costs and Returns of Human Migration. The journal of political economy, 70, 80-93. https://doi.org/10.1086/258726

Valero-Matas, J. A., Coca, J. R. y Valero-Otero, I. (2014). Análisis de la inmigración en España y la crisis económica. Papeles de Población, 20(80), 9-45.

Weiss, Y., Sauer, R. M. y Gotlibovski, M. (2003). Immigration, Search, and Loss of Skill. Journal of Labor Economics, 21(3), 557-592. https://doi.org/ http://dx.doi.org/10.1086/374959

Williams, A. y V. Baláž. (2005). What Human Capital, Which Migrants? Returned Skilled Migration to Slovakia from the UK. International Migration Review, 39(2), 439-468.

Williams, A. M. (2006). Lost in translation: International migration, learning and knowledge. Progress in Human Geography, 30(5), 588-607. 